Marquette University

e-Publications@Marquette

$12-2-2019$

\title{
Spectroscopic and Computational Comparisons of Thiolate- Ligated Ferric Nonheme Complexes to Cysteine Dioxygenase: Second-Sphere Effects on Substrate (Analogue) Positioning
}

\author{
Anne A. Fischer \\ Marquette University \\ Joshua R. Miller \\ University of Wisconsin - Madison \\ Richard J. Jodts \\ University of Wisconsin - Madison \\ Danushka M. Ekanayake \\ Marquette University \\ Sergey V. Lindeman \\ Marquette University, sergey.lindeman@marquette.edu
}

See next page for additional authors

Follow this and additional works at: https://epublications.marquette.edu/chem_fac

Part of the Chemistry Commons

\section{Recommended Citation}

Fischer, Anne A.; Miller, Joshua R.; Jodts, Richard J.; Ekanayake, Danushka M.; Lindeman, Sergey V.; Brunold, Thomas C.; and Fiedler, Adam T., "Spectroscopic and Computational Comparisons of ThiolateLigated Ferric Nonheme Complexes to Cysteine Dioxygenase: Second-Sphere Effects on Substrate (Analogue) Positioning" (2019). Chemistry Faculty Research and Publications. 991.

https://epublications.marquette.edu/chem_fac/991 


\section{Authors}

Anne A. Fischer, Joshua R. Miller, Richard J. Jodts, Danushka M. Ekanayake, Sergey V. Lindeman, Thomas C. Brunold, and Adam T. Fiedler 
Marquette University

\title{
e-Publications@Marquette
}

\section{Chemistry Faculty Research and Publications/College of Arts and Sciences}

This paper is NOT THE PUBLISHED VERSION; but the author's final, peer-reviewed manuscript. The published version may be accessed by following the link in the citation below.

Inorganic Chemistry, Vol. 58, No. 24 (December 2, 2019): 16487-16499. DOI. This article is C American Chemical Society Publications and permission has been granted for this version to appear in ePublications@Marquette. American Chemical Society Publications does not grant permission for this article to be further copied/distributed or hosted elsewhere without the express permission from American Chemical Society Publications.

\section{Spectroscopic and Computational Comparisons of Thiolate-Ligated Ferric Nonheme Complexes to Cysteine Dioxygenase: Second-Sphere Effects on Substrate (Analogue) Positioning}

\author{
Anne A. Fischer \\ Department of Chemistry, Marquette University, Milwaukee, Wisconsin \\ Joshua R. Miller \\ Department of Chemistry, University of Wisconsin-Madison, Madison, Wisconsin \\ Richard J. Jodts \\ Department of Chemistry, University of Wisconsin-Madison, Madison, Wisconsin \\ Danushka M. Ekanayake \\ Department of Chemistry, Marquette University, Milwaukee, Wisconsin \\ Sergey V. Lindeman \\ Department of Chemistry, Marquette University, Milwaukee, Wisconsin
}




\section{Thomas C. Brunold}

Department of Chemistry, University of Wisconsin-Madison, Madison, Wisconsin

Adam T. Fiedler

Department of Chemistry, Marquette University, Milwaukee, Wisconsin

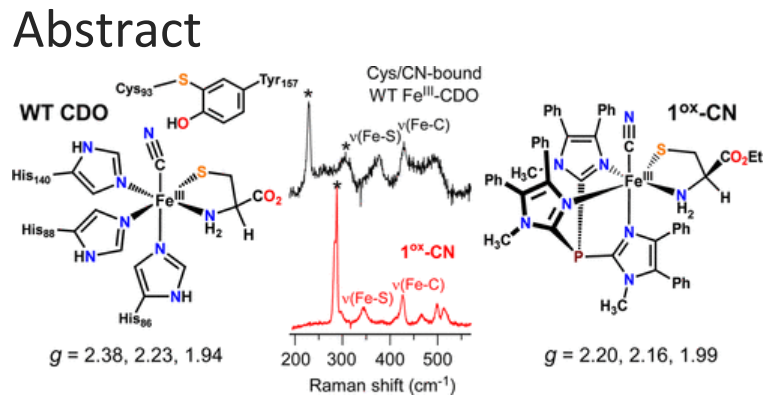

Parallel spectroscopic and computational studies of iron(III) cysteine dioxygenase (CDO) and synthetic models are presented. The synthetic complexes utilize the ligand tris(4,5-diphenyl-1-methylimidazol-2-yl)phosphine (Ph2 TIP), which mimics the facial three-histidine triad of CDO and other thiol dioxygenases. In addition to the previously reported [Fe" (CysOEt) ( $\left.{ }^{\mathrm{Ph} 2} \mathrm{TIP}^{\prime \prime}\right) \mathrm{BPh}_{4}(\mathbf{1}$; CysOEt is the ethyl ester of anionic L-cysteine), the formation and crystallographic characterization of [Fe" (2-MTS) $\left.\left({ }^{\mathrm{Ph} 2} \mathrm{TIP}\right)\right] \mathrm{BPh}_{4}(2)$ is reported, where the methyl 2thiosalicylate anion (2-MTS) resembles the substrate of 3-mercaptopropionate dioxygenase (MDO). Oneelectron chemical oxidation of $\mathbf{1}$ and $\mathbf{2}$ yields ferric species that bind cyanide and azide anions, which have been used as spectroscopic probes of $\mathrm{O}_{2}$ binding in prior studies of $\mathrm{Fe}^{\mathrm{III}}-\mathrm{CDO}$. The six-coordinate $\mathrm{Fe} \mathrm{III}^{\mathrm{II}}-\mathrm{CN}$ and Fe $\mathrm{III}_{-}$ $\mathrm{N}_{3}$ adducts are examined with UV-vis absorption, electron paramagnetic resonance (EPR), and resonance Raman (rRaman) spectroscopies. In addition, UV-vis and rRaman studies of cysteine- and cyanide-bound Fe ${ }^{\text {III- }}$ CDO are reported for both the wild-type (WT) enzyme and C93G variant, which lacks the Cys-Tyr cross-link that is present in the second coordination sphere of the WT active site. Density functional theory (DFT) and ab initio calculations are employed to provide geometric and electronic structure descriptions of the synthetic and enzymatic Fe"l' adducts. In particular, it is shown that the complete active space self-consistent field (CASSCF) method, in tandem with $n$-electron valence state second-order perturbation theory (NEVPT2), is capable of elucidating the structural basis of subtle shifts in EPR $g$ values for low-spin Fe"ll species.

\section{Synopsis}

The geometric and electronic structures of thiolate-ligated Fe ${ }^{\text {III }}$ complexes of relevance to the active sites of thiol dioxygenases have been elucidated with spectroscopic and computational methods. Data collected for the synthetic models are compared to those previously obtained for the analogous enzymatic species, and newly

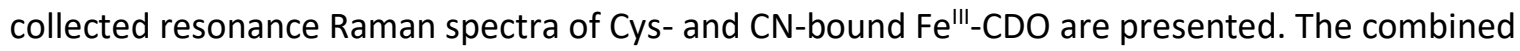
enzymatic/synthetic approach reveals that second-sphere residues perturb the positions of substrate (analogues) coordinated to the nonheme iron site of CDO.

\section{Introduction}

Thiol dioxygenases (TDOs) are a family of mononuclear nonheme iron dioxygenases that catalyze the $\mathrm{O}_{2}-$ dependent oxidation of L-cysteine (Cys) or its derivatives to the corresponding sulfinic acids $\left(\mathrm{RSO}_{2} \mathrm{H} ; \underline{\mathrm{Scheme}}\right.$ 1).(1) Two TDOs are known to operate in mammalian cells: namely, cysteine dioxygenase (CDO) and cysteamine dioxygenase (ADO). CDO regulates the intracellular concentration of exogenous Cys by performing the first step in its catabolism into small metabolites.(2-4) ADO has been shown to catalyze a key step in the degradation of coenzyme $A$ to (hypo)taurine, $(5)$ although a recent report argued that its primary function is to oxidize aminoterminal Cys residues of proteins in response to hypoxia.(6) Bacterial CDOs have also been discovered. $(7,8) \mathrm{A}$ 
third type of TDO, 3-mercaptopropionate (3-mpa) dioxygenase (MDO), has been isolated from certain soil bacteria.(9-11) X-ray structures of CDOs from various organisms reveal a common iron coordination geometry consisting of three His residues in a facial orientation (the 3-His triad). $(8,12-14)$ The active sites of $A D O(15)$ and $\mathrm{MDO}(8,11)$ also feature a 3-His triad, although a crystal structure of the former is currently lacking. The thiolate and amino donors of L-Cys bind directly to the Fe" center in the enzyme-substrate complex, yielding a fivecoordinate geometry primed for $\mathrm{O}_{2}$ binding. $(12,13)$ In contrast, a recent study suggested that only the thiolate moiety of 3-mpa binds to the Fe center of $\mathrm{MDO},(10)$ although bidentate coordination involving the carboxylate group has also been proposed by Jameson et al.(16)

L-cysteine

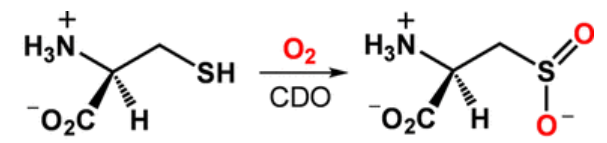

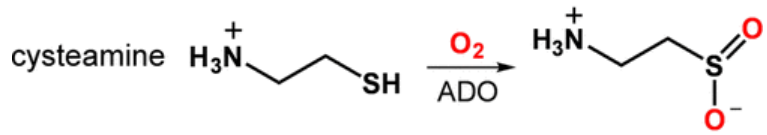

3-mpa<smiles>O=C(O)CCSCCC(=O)O[Na]</smiles>

Scheme 1. Reactions Catalyzed by Thiol Dioxygenases

Even though the first-sphere coordination environment is conserved among all TDOs, these enzymes exhibit significant variability in the second (or outer) coordination sphere. Eukaryotic CDOs are distinguished by a posttranslational cross-link between two conserved residues (Cys93 and Tyr157) located 3.3 $\AA$ from the Fe center (Figure 1).(13,17-19) This cross-link is generated during multiple turnovers of the newly formed enzyme,(17-19) and although it is not required for catalysis, its presence causes a significant (at least 20-fold) increase in CDO activity.(20) Alternatively, bacterial CDOs lack the Cys-Tyr cross-link yet maintain catalytic activities similar to those of eukaryotic CDOs.(8) The catalytic function of the cross-link remains an open question, but recent studies suggest it plays a role in substrate binding/selectivity and discourages the binding of a water molecule to the Cys-bound Fe"l-CDO active site.(13) CDOs also feature a conserved Arg residue (R60) that stabilizes the carboxylate group of bound L-Cys. MDOs lack this Arg residue, and its position in the active site is occupied instead by GIn. This change likely accounts for the ability of MDOs to oxidize all known TDO substrates (L-Cys, cysteamine, and 3-mpa),(10,21) whereas CDOs exhibit a high degree of substrate specificity.(22)

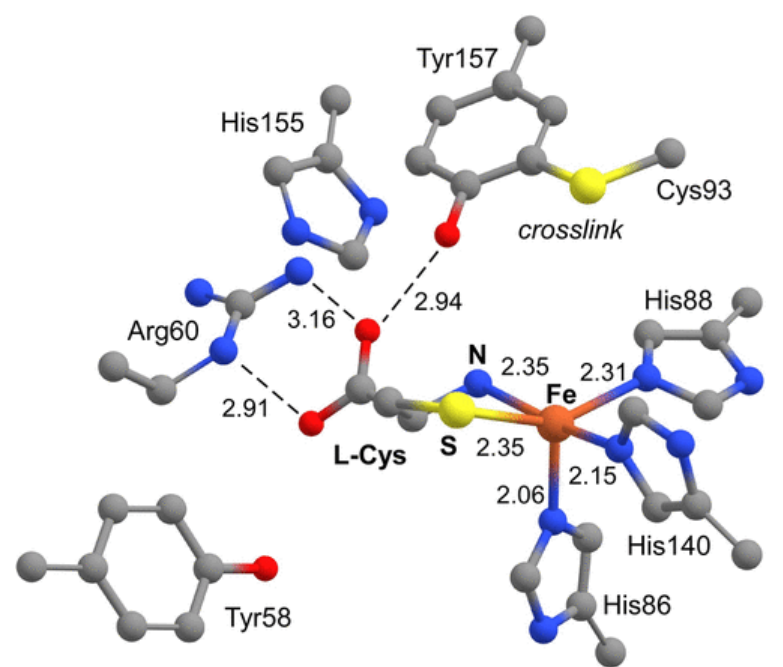

Figure 1. Crystallographic structure of the Cys-bound CDO active site derived from PDB entry 4IEV.(12) 
The structural and functional effect of the protein environment on iron oxygenases can be probed by treating the enzyme with small molecules that bind to the iron center in a manner similar to that of $\mathrm{O}_{2}$. Surrogates of $\mathrm{O}_{2}$ and its one-electron-reduced derivative, superoxide, include nitrosyl, carbonyl, azido, and cyano ligands. Binding of these ligands to the active site gives rise to distinctive spectroscopic features that report on noncovalent interactions with second-sphere groups.(23-27) Recently, the Liu group reported X-ray structures of cross-linked and non-cross-linked Fe"-CDO bound to both NO and Cys.(28) The Brunold and Pierce groups applied a similar strategy to Fe"ll-CDO by treating the oxidized enzyme with either azide(29) or cyanide.(30) These studies found that azide occupies a prebinding site in the enzyme but is unable to coordinate directly to the Fe ${ }^{\text {III }}$ center of substrate-bound CDO. Alternatively, upon treatment with excess cyanide, the high-

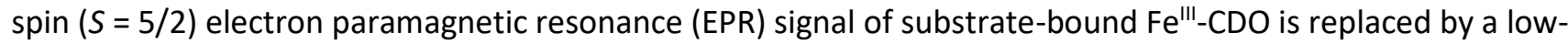
spin $(S=1 / 2)$ signal, indicating the formation of a six-coordinate ternary complex.(30) Significantly, the EPR $g$ values of the cyano adduct were shown to be sensitive to changes in the second coordination sphere, such as the formation of the Cys-Tyr cross-link.

The interpretation of spectroscopic data collected for metalloenzymes is often aided by comparison to data obtained for synthetic complexes that replicate key aspects of the active site. In 2016, we reported the synthesis of a functional CDO model, [Fe" (CysOEt) $\left.{ }^{\mathrm{Ph} 2}{ }^{\mathrm{TIP}}\right) \mathrm{BPh}_{4}\left(\mathbf{1}\right.$; $\underline{\text { Scheme } 2)}$, where ${ }^{\mathrm{Ph} 2} \mathrm{TIP}$ is tris(4,5-diphenyl-1methylimidazol-2-yl)phosphine and CysOEt is the ethyl ester of anionic L-Cys.(31) Two factors make complex 1 the most structurally accurate model of the CDO active sites prepared to date: (i) the 2TIP $^{\text {Ph2 }}$ supporting ligand reproduces the neutral charge and all-imidazole coordination of the 3-His triad and (ii) the "substrate" ligand is not tethered to the supporting ligand, as in several other CDO mimics.(32-35) Because complex 1 accurately reproduces the first coordination sphere of the enzyme, while lacking the corresponding active-site pocket, comparison of its spectroscopic features to those of the enzyme provides a unique opportunity for elucidating first- and second-sphere contributions to the geometric and electronic structures of CDO.

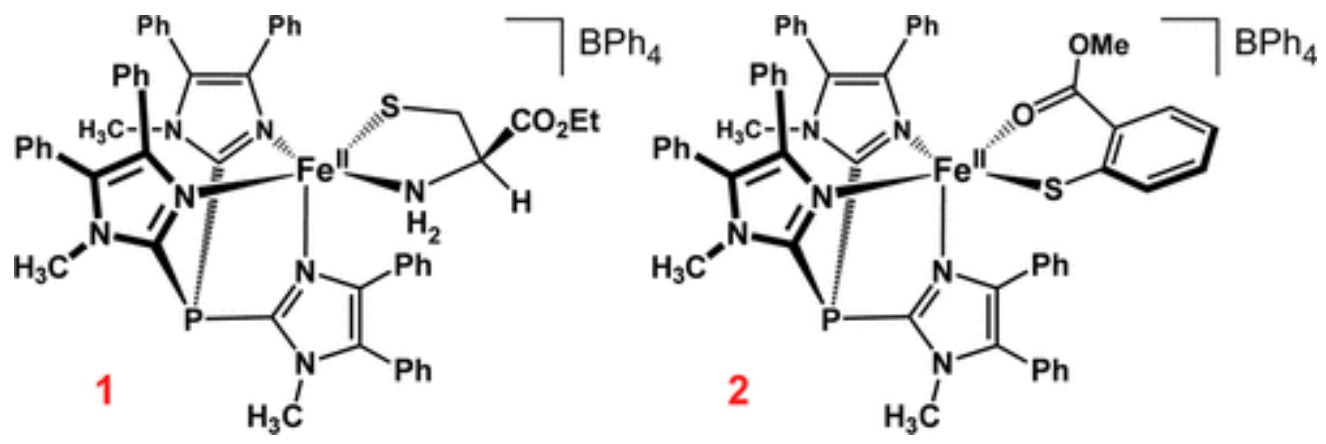

Scheme 2. Schematic Drawing of Complexes 1 and 2

In the present study, we have generated oxidized derivatives of 1 bound to azide and cyanide ligands and examined these Fe $\mathrm{Fe}^{\text {III }}$ species with an assortment of spectroscopic and computational methods. We also report the synthesis and characterization of a new TDO model, [Fe"(2-MTS)( $\left.\left.{ }^{\mathrm{Ph} 2} \mathrm{TIP}\right)\right] \mathrm{BPh}_{4}(\mathbf{2}$; $\underline{\text { Scheme } 2})$, where 2-MTS is the anion of methyl 2-thiosalicylate. The structure of $\mathbf{2}$ has similarities to the substrate-bound form of MDO, and

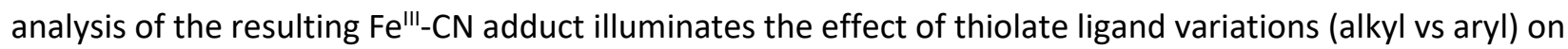
electronic and spectral features. Our approach has employed both EPR and resonance Raman (rRaman) spectroscopies, which are complementary and responsive to minor changes in structure. Herein, the resulting spectra are compared to those previously obtained for the analogous enzymatic species, and we also present

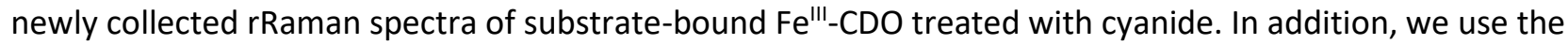
combined enzyme/model data to test the ability of density functional theory (DFT) and ab initio calculations to predict subtle shifts in spectroscopic parameters upon changes in the $\mathrm{Fe}^{\text {III }}$ coordination environment. These studies demonstrate that the complete active space self-consistent field (CASSCF) method, when it is used in 
conjunction with $n$-electron valence state second-order perturbation theory (NEVPT2), provides very accurate $g$ values for low-spin Fe ${ }^{\text {III }}$ sites in both synthetic and protein environments.

\section{Experimental and Computational Methods}

\section{General Considerations}

All reagents and solvents were purchased from commercial sources and used as received without further purification unless stated otherwise. Dichloromethane $\left(\mathrm{CH}_{2} \mathrm{Cl}_{2}\right)$ was purified and dried using a solvent purification system purchased from Vacuum Atmospheres. The synthetic Fe" complexes (1 and $\mathbf{2}$ ) were prepared and stored under an inert atmosphere in a Vacuum Atmospheres Omni-Lab glovebox. Solvents were deoxygenated prior to use in the glovebox and stored over molecular sieves. The syntheses of $\left[\mathrm{Fe}\left({ }^{\mathrm{Ph} 2} \mathrm{TIP}\right)(\mathrm{MeCN})_{3}\right](\mathrm{OTf})_{2}(36)$ and complex $1 \underline{(31)}$ were reported previously.

\section{Synthesis of $\left[\mathrm{Fe}^{\| \prime}(2-\mathrm{MTS})\left({ }^{\mathrm{Ph} 2} \mathrm{TIP}^{\mathrm{N}}\right) \mathrm{BPh}_{4}(2)\right.$}

Methyl 2-thiosalicylate $(27.5 \mu \mathrm{L}, 0.20 \mathrm{mmol})$ and $\mathrm{NEt}_{3}(30.7 \mu \mathrm{L}, 0.22 \mathrm{mmol})$ were dissolved in $\mathrm{CH}_{2} \mathrm{Cl}_{2}$ and stirred for $30 \mathrm{~min}$. Addition of $\left[\mathrm{Fe}\left({ }^{\mathrm{Ph} 2} \mathrm{TIP}\right)(\mathrm{MeCN})_{3}\right](\mathrm{OTf})_{2}(0.242 \mathrm{~g}, 0.20 \mathrm{mmol})$ yielded a red-orange solution that was stirred for $1 \mathrm{~h}$, followed by removal of solvent under vacuum. The resulting orange solid (i.e., 2-OTf) was dissolved in $\mathrm{CH}_{3} \mathrm{OH}(10 \mathrm{~mL})$ and filtered. Combination with a methanolic solution of $\mathrm{NaBPh}_{4}(0.068 \mathrm{~g}, 0.20 \mathrm{mmol})$ caused immediate formation of an orange-yellow precipitate, which was isolated by filtration. This solid was taken up in a small amount of $\mathrm{CH}_{2} \mathrm{Cl}_{2}$ and layered with $\mathrm{MeOH}$, which provided an orange-yellow solid that was collected after 1 day and dried in vacuo (yield 62\%). Anal. Calcd for $\mathrm{FeC}_{80} \mathrm{H}_{66} \mathrm{BN}_{6} \mathrm{O}_{2} \mathrm{PS}\left(\mathrm{M}_{\mathrm{w}}=1273.11 \mathrm{~g} \mathrm{~mol}^{-1}\right): \mathrm{C}$, 75.47; H, 5.22; N, 6.60. Found: C, 74.10; $\mathrm{H}, 5.68 ; \mathrm{N}, 6.80$. UV-vis $\left[\lambda_{\max }, \mathrm{nm}\left(\varepsilon, \mathrm{M}^{-1} \mathrm{~cm}^{-1}\right)\right.$ in $\left.\mathrm{CH}_{2} \mathrm{Cl}_{2}\right]: 380$ (5100), 675 (80). FTIR $\left(\mathrm{cm}^{-1}, \mathrm{CH}_{2} \mathrm{Cl}_{2}\right): v 1651$ [v(C=0)], 1582, 1504, 1062, 1030. ${ }^{1} \mathrm{H} \mathrm{NMR}\left(400 \mathrm{MHz}, \mathrm{CDCl}_{3}\right): \delta 43.6(\mathrm{~s}, 1 \mathrm{H}$, 2-MTS), 36.8 (s, 1H, 2-MTS), 17.2 (s, 9H, $\left.-\mathrm{NCH}_{3}\right), 16.5$ (s, 3H, $\left.-\mathrm{OCH}_{3}\right), 8.47$ (s, 3H, $\left.{ }^{\mathrm{Ph} 2} \mathrm{TIP}\right), 8.29$ (s, 8H, BPh 4$), 7.65$ $\left(\mathrm{s}, 8 \mathrm{H}, \mathrm{BPh}_{4}\right), 7.38\left(\mathrm{~s}, 4 \mathrm{H}, \mathrm{BPh}_{4}\right), 6.73\left(\mathrm{~s}, 6 \mathrm{H},{ }^{\mathrm{Ph} 2} \mathrm{TIP}\right), 5.83\left(\mathrm{~s}, 3 \mathrm{H},{ }^{\mathrm{Ph}} 2 \mathrm{TIP}\right), 4.85$ (s, 6H, $\left.{ }^{\mathrm{Ph} 2} \mathrm{TIP}\right), 3.10$ (s, 6H, $\left.{ }^{\mathrm{Ph} 2} \mathrm{TIP}\right)$, -0.52 (s, 1H, 2-MTS), -15.2 (br s, 6H, ${ }^{\text {Ph2 }}$ TIP), -17.1 (s, 1H, 2-MTS) ppm.

\section{X-ray Crystallography}

Orange crystals of 2-OTf suitable for crystallographic analysis were grown by layering a concentrated $\mathrm{CH}_{2} \mathrm{Cl}_{2}$ solution with pentane. Details concerning the acquisition of crystallographic data are provided in the Supporting Information. The structure of 2-OTf contains two symmetrically independent units. In the second crystallographic unit, one of the phenyl substituents of the Ph2 TIP ligand is rotationally disordered, as is the entire triflate counterion. In addition, two partially occupied positions containing $\mathrm{CH}_{2} \mathrm{Cl}_{2}$ molecules were positively localized within the layers, while the remaining solvent was accounted for using a solvent-mask procedure.

Crystallographic data for complex 2-0Tf: $\mathrm{C}_{57} \mathrm{H}_{46} \mathrm{~F}_{3} \mathrm{FeN}_{6} \mathrm{O}_{5} \mathrm{PS}_{2} \cdot 0.5 \mathrm{CH}_{2} \mathrm{Cl}_{2}, \mathrm{Mr}_{\mathrm{r}}=1145.42 \mathrm{~g} \mathrm{~mol}^{-1}$, monoclinic, space group $C 2 / c, a=46.4436(4) \AA, b=16.71596(15) \AA, c=30.6899(2) \AA, \alpha=90^{\circ}, \beta=89.9026(8)^{\circ}, \gamma=90^{\circ}, V=$ 23826.0(3) $\AA^{3}, Z=16, \rho=1.282 \mathrm{~g} \mathrm{~cm}^{-3}, \mu=3.902 \mathrm{~mm}^{-1}, \lambda=1.5418 \AA$, reflections collected 120390 , independent reflections $23968\left(R_{\text {int }}=0.0324\right), 1518$ parameters (127 restraints), R1 $=0.0503$ and $w R 2=0.1477$ for $I \geq 2 \sigma(I), R 1$ $=0.0547$ and $w R 2=0.1532$ for all data. Crystallographic data (CIF) can be obtained from the Cambridge Crystallographic Data Centre using the deposition number $\underline{1945809}$.

\section{Preparation of Synthetic Fe III-Cyano and -Azido Adducts}

Solutions of $\mathbf{1}$ (or 2 ) in $\mathrm{CH}_{2} \mathrm{Cl}_{2}$ were prepared in the glovebox and then cooled to either -78 or $-70{ }^{\circ} \mathrm{C}$. An anaerobic stock solution of $[\mathrm{AcFc}] \mathrm{BF}_{4}\left(\mathrm{AcFc}=\right.$ acetylferrocenium) in $\mathrm{CH}_{2} \mathrm{Cl}_{2}$ was also generated. Injection of 1 equiv of $\left[\mathrm{AcFC}_{\mathrm{B}} \mathrm{BF}_{4}\right.$ into the cooled solution caused a color change indicative of $\mathbf{1}^{\mathbf{0 x}}$ or $\mathbf{2}^{\mathbf{0 x}}$ formation. Formation of the cyano adducts was achieved by subsequent addition of 10-50 equiv of $\mathrm{CN}^{-}$salt (countercation $=\mathrm{K}^{+}, \mathrm{NEt}_{4}{ }^{+}$, $\mathrm{NBu}_{4}{ }^{+}$) at low temperature. The ${ }^{13} \mathrm{CN}$ and ${ }^{13} \mathrm{C}^{15} \mathrm{~N}$ adducts were generated by addition of isotopically labeled $\mathrm{KCN}$ 
salts that were solubilized in $\mathrm{CH}_{2} \mathrm{Cl}_{2}$ using 18-crown-6 ether. Formation of $\mathbf{1}^{\mathbf{0 x}}-\mathrm{N}_{\mathbf{3}}$ required addition of 5-50 equiv of $\mathrm{N}_{3}{ }^{-}$salt (countercation $=\mathrm{K}^{+}, \mathrm{NBu}_{4}{ }^{+}$) to $1^{\text {ox }}$ at low temperature, followed by warming to room temperature. The $\mathbf{1}^{\text {ox }}-\mathrm{N}_{3}$ adduct with ${ }^{15} \mathrm{~N}$-labeled azide was prepared by addition of excess $\mathrm{K}^{15} \mathrm{~N}^{14} \mathrm{~N}_{2}$ solubilized in $\mathrm{CH}_{2} \mathrm{Cl}_{2}$ using 18-crown-6 ether.

\section{Protein Purification}

Expression of the recombinant Mus musculus cdo gene was performed using Rosetta 2(DE3) E. coli cells (MilliporeSigma, Massachusetts) under control of the Lac operator in the pVP16 plasmid. The cdo gene was expressed as a fusion protein with an $\mathrm{N}$-terminal $8 \times \mathrm{His}$ and maltose binding protein (MBP) tags as previously described.(14)

The C93G CDO variant was created using site-directed mutagenesis (SDM) via PCR as previously described,(37) with the exception that Phusion Master Mix with GC buffer (Thermo Scientific, Massachusetts) and $E$. coli $10 \mathrm{G}$ chemically competent cells (Lucigen, Wisconsin) were used instead. The primers used for SDM can be found in the Supporting Information. Cell growth and protein purification were performed as before,(38) with some changes. Cells were grown in lysogeny broth (LB) containing chloramphenicol, ampicillin, and ferrous ammonium sulfate $\left[\left(\mathrm{NH}_{4}\right)_{2} \mathrm{Fe}\left(\mathrm{SO}_{4}\right)_{2}\right](34 \mu \mathrm{g} / \mathrm{mL}, 100 \mu \mathrm{g} / \mathrm{mL}$, and $110 \mu \mathrm{M}$, respectively). Gene overexpression was induced by adding isopropyl $\beta$-D-1-thiogalactopyranoside (IPTG) to a final concentration of $80.5 \mu \mathrm{M}$, D-lactose to a final concentration of $8 \mathrm{mM}$, and Casamino acids to a final concentration of $0.20 \%(\mathrm{w} / \mathrm{v})$. All buffers used had a pH of 8. Cell pellets were resuspended in $25 \mathrm{mM}$ HEPES buffer with rLysozyme (MilliporeSigma, Massachusetts) and sonicated on ice for $30 \mathrm{~min}$. The lysed solution was then centrifuged at $48400 \mathrm{~g}$ and $4{ }^{\circ} \mathrm{C}$ for $75 \mathrm{~min}$. Protein bound to the amylose column was eluted with buffer containing $25 \mathrm{mM}$ HEPES, $200 \mathrm{mM} \mathrm{NaCl}$, and $50 \mathrm{mM}$ maltose. The $\mathrm{N}$-terminal $8 \times$ His and $\mathrm{MBP}$ tags were then removed from CDO by incubating the solution with tobacco etch virus (TEV) protease overnight at room temperature. Tag-free CDO was isolated using subtractive immobilized metal affinity chromatography (IMAC) with a Nil nitrilotriacetic acid (NTA) agarose resin (GE Healthcare, Illinois).

C93G CDO samples for spectroscopy were reconstituted with Fe" to increase the increase the fraction of Febound CDO active sites. This was accomplished by adding a 2 -fold excess of $\left[\left(\mathrm{NH}_{4}\right)_{2} \mathrm{Fe}\left(\mathrm{SO}_{4}\right)_{2}\right]$ to C93G CDO aerobically. After the protein and $\left[\left(\mathrm{NH}_{4}\right)_{2} \mathrm{Fe}\left(\mathrm{SO}_{4}\right)_{2}\right]$ solution was stirred for $30 \mathrm{~min}$ at $4{ }^{\circ} \mathrm{C}$, a 3 -fold excess of ammonium hexachloroiridate(IV) $\left(\left(\mathrm{NH}_{4}\right)_{2}[\mathrm{IrCl} 6]\right)$ was added and the solution was again stirred for $30 \mathrm{~min}$ at $4{ }^{\circ} \mathrm{C}$. To remove any excess $\left[\left(\mathrm{NH}_{4}\right)_{2} \mathrm{Fe}\left(\mathrm{SO}_{4}\right)_{2}\right]$ and $\left(\mathrm{NH}_{4}\right)_{2}\left[\mathrm{IrCl} \mathrm{C}_{6}\right]$, a buffer exchange using $25 \mathrm{mM}$ HEPES and $200 \mathrm{mM}$ $\mathrm{NaCl}$ solutions, in conjunction with a $10 \mathrm{kDa}$ centrifugal filter unit, was performed three times. The iron content of C93G CDO was then determined via a colorimetric assay using 2,4,6-tris(2-pyridyl)-s-triazine (TPTZ).(39) A summary of this assay can be found in the Supporting Information. To generate Cys- and CN-bound C93G Fe'II$\mathrm{CDO}$, a 10-fold molar excess of Cys over Fe'l'-bound variant protein was added to the sample. After $5 \mathrm{~min}$, a 10fold molar excess of KCN over C93G Fe'II-CDO was then added. The sample was frozen after another 5 min incubation period.

WT CDO samples for spectroscopy were prepared similarly to C93G CDO with two modifications. Namely, iron reconstitution was performed anaerobically in a glovebox and samples were subsequently treated with Chelex 100 sodium form (Sigma-Aldrich, Missouri) for $30 \mathrm{~min}$ to remove any unbound iron in solution. Samples were not treated with $\left(\mathrm{NH}_{4}\right)_{2}\left[\mathrm{IrCl}_{6}\right]$; thus, no buffer exchange was performed.

\section{Spectroscopic Data}

UV-vis absorption spectra were collected with either an Agilent 8453 diode array spectrometer (synthetic samples) or Varian Cary 4 Bio spectrometer (protein samples). The former was equipped with a Unisoku Scientific Instruments (Osaka, Japan) cryostat for low-temperature measurements. ${ }^{1} \mathrm{H}$ NMR spectra were 
measured on a Varian $400 \mathrm{MHz}$ spectrometer. Elemental analyses were performed at Midwest Microlab, LLC, in Indianapolis, IN. Infrared (IR) spectra were measured with a Thermo Scientific Nicolet iS5 FTIR spectrophotometer. X-band EPR spectra were gathered using a Bruker EMX instrument equipped with an ER4112 SHQ resonator. EPR data were collected at liquid He temperatures (5-15 K) using a ColdEdge/Bruker RDK-408 Stinger recirculating cryocooler. The program EasySpin (version 5)(40) was employed to conduct simulations of experimental EPR spectra.

The resonance Raman data were measured using $647.1 \mathrm{~nm}$ excitation from a Coherent I-302C Kr${ }^{+}$laser. The laser power at the sample was between 30 and $50 \mathrm{~mW}$ for the synthetic samples and $\sim 20 \mathrm{~mW}$ for the protein samples. The synthetic samples had concentrations of 5-10 mM on the basis of the initial quantity of precursor complex (1 or 2). The preparation of protein samples for rRaman analysis is described in further detail above. Light scattered from frozen samples in liquid $\mathrm{N}_{2}$ was collected using a $135^{\circ}$ backscattering arrangement and dispersed by an Acton Research triple monochromator featuring a 1200 grooves/mm grating. The scattered light was detected and analyzed with a Princeton Instruments Spec X:100BR deep depletion, back-thinned CCD camera. Baselines of the rRaman spectra were corrected using piecewise functions in the program IGOR to remove broad background contributions. Peak positions were calibrated against the $984 \mathrm{~cm}^{-1}$ peak of a $\mathrm{K}_{2} \mathrm{SO}_{4}$ standard or ice peak at $228 \mathrm{~cm}^{-1}$ for protein samples.

\section{Computational Methods}

All calculations were performed with the ORCA software package (version 3.0 or 4.0) developed by Dr. F. Neese (MPI for Chemical Energy Conversion).(41) Computational models of $\mathbf{1}^{\mathbf{o x}}-\mathbf{C N}, \mathbf{2}^{\mathbf{o x}}-\mathbf{C N}$, and $\mathbf{1}^{\mathbf{0 x}}-\mathbf{N}_{\mathbf{3}}$ were generated via density functional theory (DFT) calculations that employed Becke's three-parameter hybrid functional for exchange along with the Lee-Yang-Parr correlation functional (B3LYP).(42,43) The geometry optimizations used Ahlrichs' valence triple- $\zeta$ basis set combined with polarization functions on main-group and transition-metal

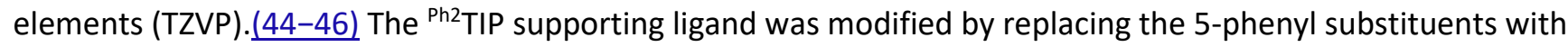
hydrogen atoms. Computational times were reduced by applying the resolution of identity and chain of sphere (RIJCOSX) approximation(47) and the TZV/J auxiliary basis set.(48) Only real vibrational frequencies were computed for the optimized structures, indicating that they correspond to local energy minima. Active-site models of CDO in its cross-linked $(\alpha)$ and non-cross-linked $(\beta)$ forms were obtained from previous QM/MM calculations reported by Li et al.(30) Atomic coordinates of all computational models are provided in Tables S4$\underline{\mathrm{S10}}$. For each Fe'III-CN adduct, the composition of the singly occupied molecular orbital (SOMO) was determined through a natural orbital calculation on the basis of the DFT/B3LYP results. Computational results were visualized with the ChemCraft program.

Two different approaches were employed to compute the $\mathbf{g}$ tensor of $\mathbf{1}^{\mathbf{0 x}}$ - $\mathbf{C N}$. The first method determined spinorbit coupling contributions by solving the coupled-perturbed self-consistent field (CP-SCF) equations.(49-52) These calculations employed the B3LYP functional, RIJCOSX approximation, and TZVP basis set. The second approach utilized the complete active space self-consistent field (CASSCF) based method along with $n$-electron valence state second-order perturbation theory (NEVPT2). $(53,54)$ These calculations were based on unrestricted natural orbitals derived from single-point DFT/B3LYP calculations. The CASSCF/NEVPT2 calculations used either a split valence basis set with polarization (SVP with auxiliaries) or the TZVP basis set described above. The impact of active-space size and basis set size on computed $g$ values was analyzed for $\mathbf{1}^{\text {ox }}$ $\mathbf{C N}$, and the results are provided in Table $\mathbf{S 2}$. These results suggested that the most appropriate active space is CAS $(11,13)$, which consists of the five Fe $3 d$ orbitals, a second Fe d shell, and three CysOEt-based orbitals. The CAS $(11,13)$ approach was then applied to the other FeCN adducts. Ten doublet roots were calculated in each case. 


\section{Results and Discussion}

\section{Synthesis and X-ray Structure of a Substrate-Bound MDO Model}

Following our earlier procedure for the synthesis of complex 1,(31) [Fe"(2-MTS)( ${ }^{\text {Ph2 }}$ TIP)]OTf (2-OTf) was prepared by treating the $\left[\mathrm{Fe}^{\mathrm{II}}\left({ }^{\mathrm{Ph} 2} \mathrm{TIP}\right)(\mathrm{MeCN})_{3}\right](\mathrm{OTf})_{2}$ precursor with methyl 2-thiosalicylate in the presence of $\mathrm{NEt}_{3}$. Counteranion metathesis with $\mathrm{NaBPh}_{4}$ in $\mathrm{MeOH}$ provided [Fe"(2-MTS)( $\left.\left.{ }^{\mathrm{Ph} 2} \mathrm{TIP}\right)\right] \mathrm{BPh}_{4}$ (2) as a precipitate that was collected and dried to give a yellow powder. Yellow-orange crystals of 2-OTf for X-ray diffraction experiments were grown by layering a concentrated $\mathrm{CH}_{2} \mathrm{Cl}_{2}$ solution with pentane. The unit cell of 2-OTf consists of two symmetrically independent $\mathrm{Fe}^{\text {II }}$ complexes with similar five-coordinate geometries. The three imidazole donors of ${ }^{\mathrm{Ph} 2} \mathrm{TIP}$ are arranged facially with an average Fe- $\mathrm{N}_{\text {TIP }}$ distance of $2.15 \AA$ (Figure 2 ). These bond distances reflect the high-spin $(S=2)$ state of the Fe" center, which is also apparent in the paramagnetically shifted peaks between -20 and +50 ppm observed by ${ }^{1} \mathrm{H}$ NMR spectroscopy (Figure S1). The overall geometry is best described as distorted trigonal bipyramidal (average $\tau$ value 0.57$)(55)$ with the thiolate and carbonyl donors of 2MTS occupying equatorial and axial positions, respectively. Metric parameters for complexes $\mathbf{1}$ and 2-OTf are compared in Table S1. The two complexes exhibit nearly identical Fe-S bond distances $(\sim 2.32 \AA)$ despite the change from alkanethiolate (1) to arenethiolate (2-OTf). The distance between the Fe center and $\mathrm{O}$ atom donor of 2-MTS is $2.13 \AA$, which is considerably shorter (by $0.11 \AA$ ) than the Fe- $\mathrm{N}_{\text {amino }}$ distance measured for the CysOEt ligand of 1 . These results highlight the stability of the six-membered chelate formed by the bidendate S,O-coordination of 2-MTS.

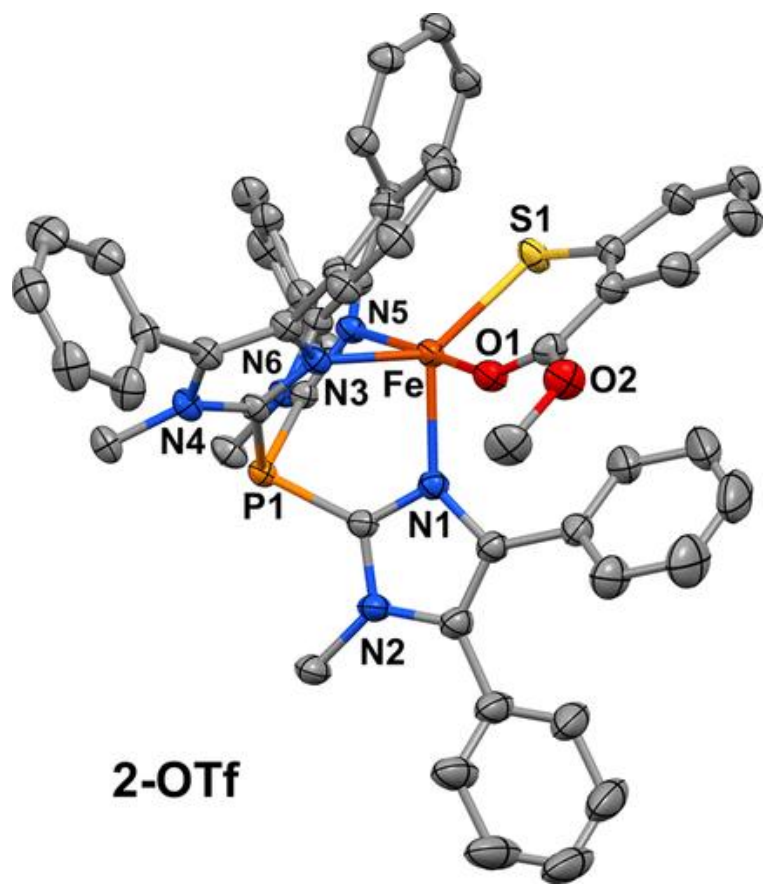

Figure 2. Thermal ellipsoid plot (50\% probability) obtained from the X-ray crystal structure of 2-OTf. The triflate counteranion, noncoordinating solvent molecules, and all hydrogen atoms are omitted for clarity.

Because of the structural similarities between 2-MTS and 3-mpa, complex $\mathbf{2}$ serves as an active-site mimic of substrate-bound Fe"-MDO. Recently, Jameson and co-workers employed docking methods to discern the position of 3-mpa within the MDO active site.(16) In the resulting model (Figure S2), the thiolate and carboxylate groups of 3-mpa coordinate trans to His91 and His142, respectively. This bidentate conformation is favored by the formation of a salt bridge between the substrate carboxylate and Arg168, which places one of the $\mathrm{O}$ atoms in proximity to the Fe center. In contrast, Pierce has suggested that the carboxylate of 3-mpa participates in a hydrogen bond with a conserved Tyr residue, resulting in thiolate-only coordination.(10) Although the X-ray structure of 2-OTf resembles the docking model of Jameson, the absence of outer-sphere residues makes it 
impossible to draw firm conclusions from our synthetic efforts. Thus, future structural and spectroscopic studies of MDOs are required to determine the mode of substrate binding.

\section{Formation and Spectroscopic Features of Ferric Cyano and Azido Species}

Analysis with cyclic voltammetry (CV) revealed that complex 1 undergoes irreversible oxidation at $+65 \mathrm{mV}$ (vs $\mathrm{Fc}^{+/ 0}$ ) in $\mathrm{CH}_{2} \mathrm{Cl}_{2}$ at room temperature. On the basis this result, we reckoned that it would be possible to generate the ferric derivative by chemical oxidation with acetylferrocenium ( $\mathrm{AcFc}^{+} ; E_{1 / 2}=+270 \mathrm{mV}$ ). (56) Indeed, treatment of 1 with 1 equiv of $\left[\mathrm{AcFc}_{\mathrm{B}} \mathrm{BF}_{4}\right.$ in $\mathrm{CH}_{2} \mathrm{Cl}_{2}$ at $-78^{\circ} \mathrm{C}$ generates a new chromophore $\left(1^{\mathrm{ox}}\right)$ with intense absorption bands at 445 and $595 \mathrm{~nm}$ (Figure $3 \mathrm{a}$ ). The oxidized species is stable at reduced temperatures but decays upon warming to room temperature, consistent with the irreversibility observed by CV (Figure S3). Oxidation of 2 under similar conditions $\left(T=-70^{\circ} \mathrm{C}\right)$ yields a reddish-brown species $\left(2^{\circ x}\right)$ with a similar pattern of UV-vis features, albeit red-shifted in comparison to $\mathbf{1}^{\text {ox }}$. Like $\mathbf{1}^{\text {ox }}$, the absorption features of $\mathbf{2}^{\text {ox }}$ decay upon warming to room temperature to give a featureless spectrum (Figure S3). The $\mathbf{1}^{\mathrm{ox}}$ and $\mathbf{2}^{\mathrm{ox}}$ absorption bands likely derive from thiolate to Fe ${ }^{\text {III }}$ charge transfer (CT) transitions. In support of this conclusion, X-band EPR spectra of both species (Figure S4) feature an intense derivative feature at $g=4.3$ and a much weaker peak near $g=9.4$. Such spectra are typical of mononuclear high-spin Felll complexes with rhombic symmetry $(E / D \approx 0.33)$.
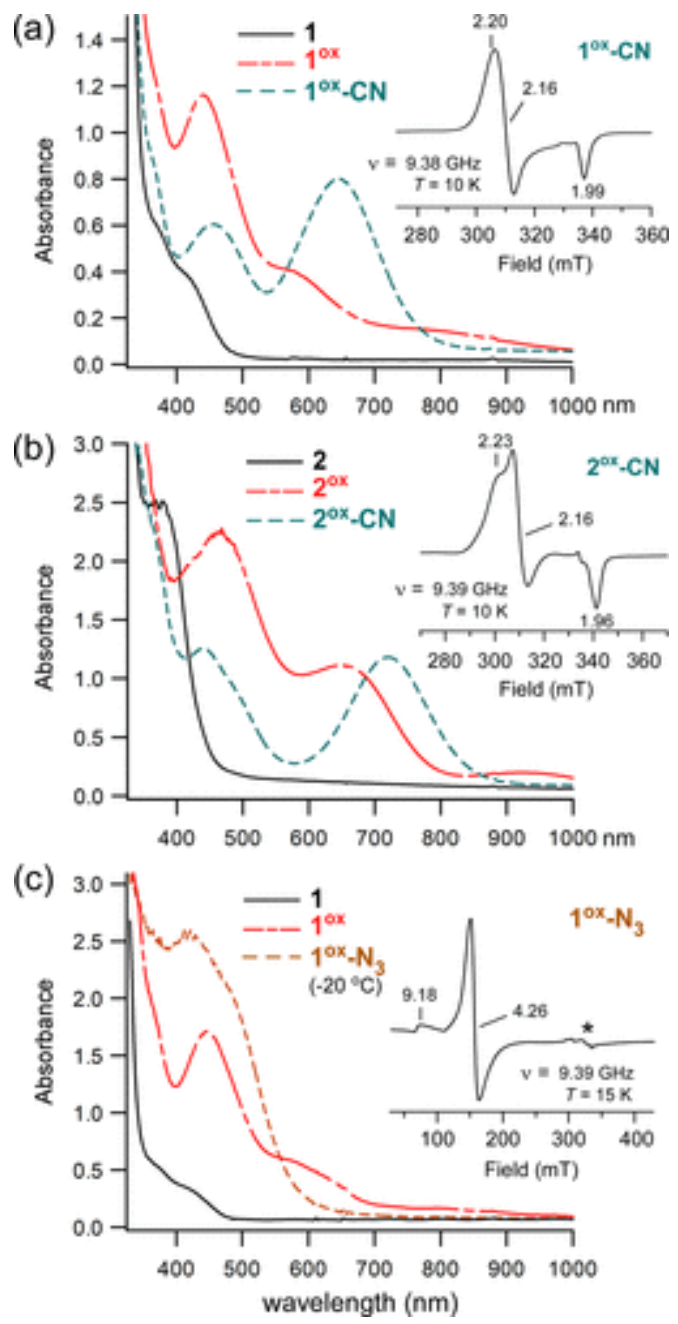

Figure 3. UV-vis and EPR spectra of oxidized derivatives of complexes $\mathbf{1}$ and $\mathbf{2}$. Absorption spectra were measured in $\mathrm{CH}_{2} \mathrm{Cl}_{2}$ at either $-78{ }^{\circ} \mathrm{C}(\mathrm{a})$ or $-70^{\circ} \mathrm{C}(\mathrm{b}, \mathrm{c})$, with the exception of the $1^{\text {ox }}-\mathrm{N}_{3}$ spectrum $\left(20^{\circ} \mathrm{C}\right)$. Samples of $\mathbf{1}^{\text {ox }}$ and $\mathbf{2}^{\text {ox }}$ were generated by treatment of $\mathbf{1}$ and $\mathbf{2}$, respectively, with 1 equiv of [AcFc]BF Further $^{\circ}$ addition of 50 equiv of (a) $\left[\mathrm{NBu}_{4}\right] \mathrm{CN}$, (b) $\left[\mathrm{NEt}_{4}\right] \mathrm{CN}$, or (c) $\left[\mathrm{NBu}_{4}\right] \mathrm{N}_{3}$ gave rise to the cyano and azido adducts (formation of the latter required warming to $20^{\circ} \mathrm{C}$ ). Initial concentration of Fe complex: (a) $0.52 \mathrm{mM}$, (b) 0.59 
$\mathrm{mM}$, and (c) $0.45 \mathrm{mM}$. Insets: X-band EPR spectra of (a) $\mathbf{1}^{\mathbf{0 x}}-\mathbf{C N}$, (b) $\mathbf{2}^{\mathbf{o x}}-\mathbf{C N}$, and (c) $\mathbf{1}^{\mathbf{0 x}}-\mathbf{N}_{\mathbf{3}}$ measured in frozen $\mathrm{CH}_{2} \mathrm{Cl}_{2}$ solutions at the indicated temperature. The microwave power was $2 \mathrm{~mW}$, and the frequency $(v)$ is indicated. The features designated by an asterisk $(*)$ arise from a copper impurity in the sample cavity.

Addition of excess cyanide anion to solutions of $\mathbf{1}^{\text {ox }}$ at low temperature results in the formation of a new teal species ( $\left.\mathbf{1}^{\text {ox }}-\mathbf{C N}\right)$. Complete conversion of $\mathbf{1}^{\text {ox }} \rightarrow \mathbf{1}^{\text {ox }}-\mathbf{C N}$ requires at least 10 equiv of cyanide anion, suggesting that the affinity is rather low. The same procedure was used to generate $\mathbf{2}^{\mathbf{0 x}}$-CN. As shown in Figure 3 , these cyanide-treated species are characterized by a strong $S \rightarrow \mathrm{Fe}^{\text {III }}$ charge transfer (CT) band at 645 (1 $\left.{ }^{\text {ox }}-\mathbf{C N}\right)$ or 720 $\mathrm{nm}\left(2^{\mathrm{ox}}-\mathrm{CN}\right)$, in addition to a second CT feature at shorter wavelength $\left(\lambda_{\max } \approx 440 \mathrm{~nm}\right)$. The energies and

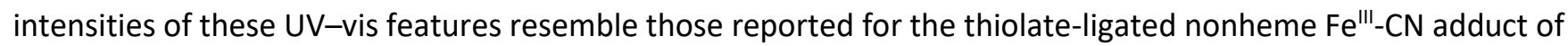
superoxide reductase (SOR).(23) Unlike their $\mathbf{1}^{\mathrm{ox}} / \mathbf{2}^{\mathrm{ox}}$ precursors, the cyanide-treated species are stable at room temperature.

As expected, cyanide coordination causes the Fe ${ }^{\text {III }}$ complexes to adopt a low-spin configuration. The EPR spectrum of $\mathbf{1}^{\text {ox }}-\mathbf{C N}$ in frozen $\mathrm{CH}_{2} \mathrm{Cl}_{2}$ exhibits a nearly axial $S=1 / 2$ signal (Figure 3a; inset) that was simulated with $g$ values of $2.204,2.161$, and 1.988 . No high-spin $S=5 / 2$ features were observed even at $10 \mathrm{~K}$, indicating full conversion of $\mathbf{1}^{\text {ox }}$ to $\mathbf{1}^{\text {ox }}-\mathbf{C N}$. The spectrum of $\mathbf{2}^{\text {ox }}-\mathbf{C N}$ (Figure $3 \mathrm{~b}$; inset) displays slightly greater rhombicity with $g$ values of 2.231, 2.161, and 1.964. Table1 compares these $g$ values to those measured by Pierce et al. for Cys-bound Fe'II-CDO treated with cyanide.(30) It is clear that the EPR signals of the CDO adducts are significantly more rhombic and anisotropic than those exhibited by the synthetic analogues. The structural factors behind these disparities will be explored in Computational Studies.

Table 1. Comparison of EPR $g$ Values Measured for (L-Cys/CN)-Bound Fe'III-CDO and Related Model Complexes

\begin{tabular}{|l|l|l|l|l|}
\hline species & $g_{1}$ & $g_{2}$ & $g_{3}$ & ref \\
\hline WT (L-Cys/CN)-bound Fe'I'-CDO & 1.937 & 2.234 & 2.379 & $(30)$ \\
\hline C93A (L-Cys/CN)-bound Fe ${ }^{\text {III-CDO }}{ }^{\text {b }}+$ & 1.951 & 2.208 & 2.343 & (30) \\
\hline $1^{\text {ox }}$-CN & 1.988 & 2.161 & 2.204 & this work \\
\hline $2^{\text {ox }}$-CN & 1.964 & 2.161 & 2.231 & this work \\
\hline
\end{tabular}

aWT enzyme with Cys93-Y157 cross-link.

${ }^{\text {b}}$ The C93A CDO variant lacks the Cys93-Y157 cross-link.

The ability of $1^{\text {ox }}$ to bind azide was also examined. Treatment of $1^{\text {ox }}$ with 50 equiv of $\left[\mathrm{NBu}_{4}\right] \mathrm{N}_{3}$ at $-80{ }^{\circ} \mathrm{C}$ results in only modest spectral changes; however, the reaction at $20{ }^{\circ} \mathrm{C}$ generates a dark brown chromophore $\left(\mathbf{1}^{\mathbf{o x}}-\mathbf{N}_{\mathbf{3}}\right)$ that displays intense absorption features in the 400-600 nm region (Figure $3 \mathrm{c}$ ). Comparison to synthetic precedents suggests that these features arise from $\mathrm{N}_{3}{ }^{-} \rightarrow \mathrm{Fe}^{\text {III }} \mathrm{CT}$ transitions, (57) although $\mathrm{S} \rightarrow \mathrm{Fe}{ }^{\text {III }} \mathrm{CT}$ bands probably also contribute to the absorption envelope. The EPR spectrum of $\mathbf{1}^{\mathrm{ox}}-\mathrm{N}_{\mathbf{3}}$ consists of a rhombic $S=5 / 2$ signal (Figure $3 \mathrm{c}$, inset) similar to that measured for $\mathbf{1}^{\mathbf{0 x}}$, indicating the complex remains high spin upon azide coordination.

The properties of the ferric-cyano and -azido adducts were further probed with rRaman spectroscopy. Excitation into the $\mathrm{S} \rightarrow \mathrm{Fe}^{\mathrm{III}} \mathrm{CT}$ band using $647.1 \mathrm{~nm}$ laser light provided the spectra of $\mathbf{1}^{\mathrm{ox}}-\mathrm{CN}$ and $\mathbf{2}^{\text {ox }}-\mathrm{CN}$ shown in Figures 4 and $\underline{5}$, respectively. These spectra display a series of features in the $300-550 \mathrm{~cm}^{-1}$ region arising from vibrations of the NC-Fe-SR unit. Peak assignments were made by comparing spectra of samples prepared with different cyanide isotopes (i.e., ${ }^{12} \mathrm{C}^{14} \mathrm{~N},{ }^{13} \mathrm{C}^{14} \mathrm{~N}$, and ${ }^{13} \mathrm{C}^{15} \mathrm{~N}$ ). The frequency of the peak at $341 \mathrm{~cm}^{-1}$ in the $\mathbf{1}^{\text {ox }}$ $\mathrm{CN}$ spectrum is characteristic of $\mathrm{v}(\mathrm{Fe}-\mathrm{S})$ modes in nonheme iron enzymes and complexes with thiolate coordination. $(23,58-65)$ This peak downshifts slightly $\left(1 \mathrm{~cm}^{-1}\right)$ upon ${ }^{13} \mathrm{CN}$ labeling due to kinematic coupling between the Fe-S and Fe-C stretching motions. The peak at $464 \mathrm{~cm}^{-1}$ in the natural abundance $\left(\mathrm{NA},{ }^{12} \mathrm{C}^{14} \mathrm{~N}\right)$ 
spectrum exhibits a similarly small isotope shift, likely corresponding to the $\mathrm{Fe}-\mathrm{N}$ stretching mode of the $-\mathrm{NH}_{2}$ donor of CysOEt.

(a)

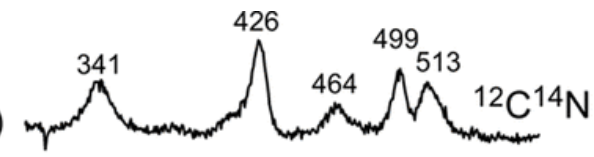

(b)

$\Delta^{13} \mathrm{C}=-1$

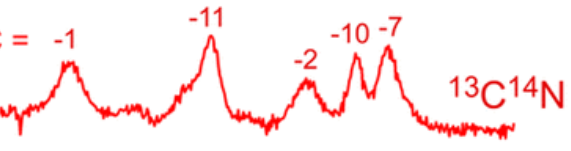

(c)

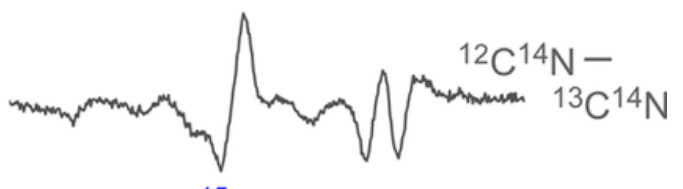

(d)

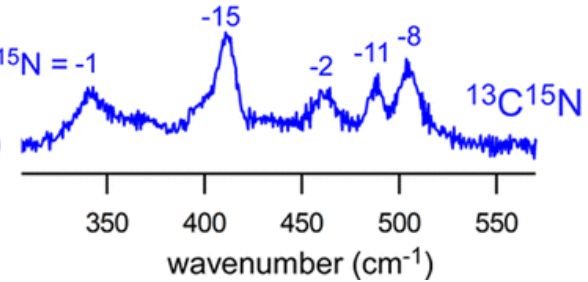

Figure 4. Resonance Raman spectra of $\mathbf{1}^{\text {ox }}$ - $\mathbf{C N}$ collected using $647.1 \mathrm{~nm}$ laser excitation ( $\sim 40 \mathrm{~mW}$ at the sample). The samples were prepared by treating $1^{\text {ox }}$ with (a) natural abundance $\mathrm{KCN}$ (50 equiv) in $\mathrm{CD}_{2} \mathrm{Cl}_{2}$, (b) $\mathrm{K}^{13} \mathrm{CN}$ (50 equiv) in $\mathrm{CD}_{2} \mathrm{Cl}_{2}$, and (d) $\mathrm{K}^{13} \mathrm{C}^{15} \mathrm{~N}$ (10 equiv) in $\mathrm{CH}_{2} \mathrm{Cl}_{2}$. The $\mathrm{KCN}$ salts were solubilized using 18 -crown- 6 ether. The difference spectrum (a-b) generated by digital subtraction is provided in (c). The ${ }^{13} \mathrm{C}$ and ${ }^{13} \mathrm{C}^{15} \mathrm{~N}$ isotope shifts relative to the NA spectrum are indicated in $\mathrm{cm}^{-1}$.

(a)

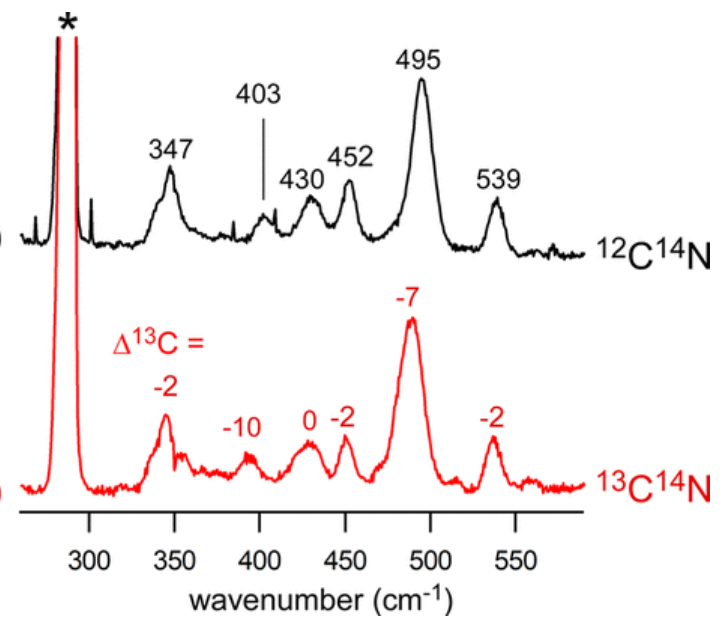

Figure 5. Resonance Raman spectra of $\mathbf{2}^{\mathbf{0 x}}-\mathbf{C N}$ collected at $77 \mathrm{~K}$ using $647.1 \mathrm{~nm}$ laser excitation ( $30 \mathrm{~mW}$ at the sample). The samples were prepared at $-78^{\circ} \mathrm{C}$ by treating $2^{\text {ox }}$ with (a) natural-abundance $\mathrm{KCN}$ (10 equiv) or (b) $\mathrm{K}^{13} \mathrm{CN}$ (10 equiv) in $\mathrm{CH}_{2} \mathrm{Cl}_{2}$. The $\mathrm{KCN}$ salts were solubilized using 18 -crown- 6 ether. The ${ }^{13} \mathrm{C}$ isotope shifts relative to the NA spectrum are indicated in $\mathrm{cm}^{-1}$. Solvent-derived peaks are indicated with an asterisk $\left({ }^{*}\right)$.

Much larger ${ }^{13} \mathrm{C}$ isotope shifts are displayed by the three peaks at 426,499 , and $513 \mathrm{~cm}^{-1}$ in the NA spectrum. These features arise from $v(\mathrm{Fe}-\mathrm{CN})$ stretching and $\delta(\mathrm{Fe}-\mathrm{C}-\mathrm{N})$ bending modes that often exhibit a substantial degree of mixing. On the basis of prior studies of $\mathrm{Fe} \mathrm{I}^{\mathrm{III}}-\mathrm{CN}$ adducts in proteins, it is known that modes with predominant $\mathrm{v}(\mathrm{Fe}-\mathrm{CN})$ character are distinguished by large shifts upon isotopic substitution of both the carbon and nitrogen atoms of the cyano ligand, whereas the frequencies of $\delta(\mathrm{Fe}-\mathrm{C}-\mathrm{N})$ modes are predominantly sensitive to isotopic substitution at the carbon atom. $(23,25,66)$ As shown in Figure 4 , the peak at $426 \mathrm{~cm}^{-1}$ in the 
NA spectrum decreases by $15 \mathrm{~cm}^{-1}$ upon ${ }^{13} \mathrm{C}^{15} \mathrm{~N}$ labeling, which is $4 \mathrm{~cm}^{-1}$ greater than the change caused by ${ }^{13} \mathrm{C}$ labeling alone. In contrast, the ${ }^{13} \mathrm{C}^{15} \mathrm{~N}$ shifts of the peaks at 499 and $513 \mathrm{~cm}^{-1}$ are nearly identical with the ${ }^{13} \mathrm{C}$ shifts. Thus, the peak at $426 \mathrm{~cm}^{-1}$ is assigned to the $v(\mathrm{Fe}-\mathrm{CN})$ stretching mode, while those at 499 and $513 \mathrm{~cm}^{-}$ ${ }^{1}$ are attributed to modes with predominately $\delta(\mathrm{Fe}-\mathrm{C}-\mathrm{N})$ bending character. Clay et al. also observed $\delta(\mathrm{Fe}-\mathrm{C}-\mathrm{N})$ bending modes around $500 \mathrm{~cm}^{-1}$ in the spectrum of $\mathrm{CN}$-treated Fe'II-SOR.(23) The observation of two $\delta(\mathrm{Fe}-\mathrm{C}-$ $\mathrm{N}$ )-based peaks for $\mathbf{1}^{\mathrm{ox}}$ - $\mathrm{CN}$ may indicate the presence of two conformations in frozen solution. An alternative explanation is that the $\mathrm{FeCN}$ geometry is nearly linear, since the frequencies of the two bending modes merge as the bond angle approaches $180^{\circ}$. The latter scenario is supported by DFT calculations (vide infra), which predict a Fe-C-N angle of $176^{\circ}$ for $1^{\text {ox }}-\mathrm{CN}$.

The rRaman spectrum of $2^{\text {ox }}$-CN exhibits peaks due to $v(\mathrm{Fe}-\mathrm{S})$ and $\mathrm{v}(\mathrm{Fe}-\mathrm{CN})$ stretching modes at 347 and $403 \mathrm{~cm}^{-}$ ${ }^{1}$, respectively (Figure 5). The feature at $452 \mathrm{~cm}^{-1}$ with a small ${ }^{13} \mathrm{C}$ isotope shift of $-2 \mathrm{~cm}^{-1}$ is tentatively assigned to a mode primarily involving stretching of the $\mathrm{Fe}-\mathrm{O}$ (carbonyl) bond. Unlike $\mathbf{1}^{\mathrm{ox}}-\mathrm{CN}$, the spectrum of $\mathbf{2}^{\text {ox }}$ $\mathrm{CN}$ displays a single $\delta(\mathrm{Fe}-\mathrm{C}-\mathrm{N})$ peak at $495 \mathrm{~cm}^{-1}$, although the higher frequency mode at $539 \mathrm{~cm}^{-1}$ likely has significant $\delta(\mathrm{Fe}-\mathrm{C}-\mathrm{N})$ and/or $v(\mathrm{Fe}-\mathrm{CN})$ character.

Raman studies of $\mathbf{1}^{\text {ox }}-\mathrm{N}_{\mathbf{3}}$ employed $488.1 \mathrm{~nm}$ laser excitation into the overlapping $\mathrm{N}_{3}{ }^{-} \rightarrow \mathrm{Fe}^{\text {III }}$ and $\mathrm{S} \rightarrow \mathrm{Fe}^{\text {III }} \mathrm{CT}$ bands. The resulting spectrum (Figure S5) exhibits an intense peak at $377 \mathrm{~cm}^{-1}$ that is assigned to the $v(\mathrm{Fe}-\mathrm{S})$ stretching mode on the basis of its frequency. This peak downshifts by $2 \mathrm{~cm}^{-1}$ when the sample is prepared with ${ }^{15} \mathrm{~N}^{14} \mathrm{~N}_{2}$-labeled azide, indicative of weak coupling to the $v(\mathrm{Fe}-\mathrm{N})$ mode of the azido ligand. For reasons that are not clear, the stretching and bending modes of the $\mathrm{Fe}^{\mathrm{III}}-\mathrm{N}_{3}$ unit are not observed directly. Nevertheless, the clear shift in the $\mathrm{v}(\mathrm{Fe}-\mathrm{S})$ frequency upon isotopic labeling of $\mathrm{N}_{3}{ }^{-}$provides direct evidence of azide coordination to the Fe ${ }^{\text {III }}$ center. The formation of $\mathbf{1}^{\mathbf{o x}}-\mathbf{N}_{\mathbf{3}}$ is notable because spectroscopic and crystallographic

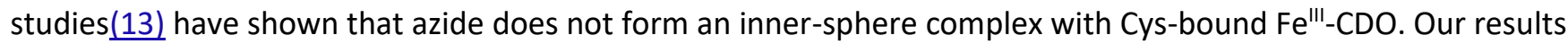
thus support the proposal that the inability of Cys-bound Fe ${ }^{\text {III }} \mathrm{CDO}$ to form an $\mathrm{Fe}^{\mathrm{III}}-\mathrm{N}_{3}$ adduct is due to a hydroxide ion occupying the sixth coordination site rather than an intrinsic lack of azide affinity by the Fe ${ }^{\text {III }}$ site.(29)

\section{Resonance Raman Studies of CN/Cys-Bound Fe'II-CDO}

Parallel studies of Cys- and CN-treated Fe ${ }^{\mathrm{II}}$-CDO were conducted to discern the effect of the protein environment on the geometric and electronic structures of the Fe"l' center. Wild-type (WT) Cys/CN-bound Fe"'I$\mathrm{CDO}$ exhibits a bluish color due to the presence of a $\mathrm{S} \rightarrow \mathrm{Fe}^{\mathrm{III}} \mathrm{CT}$ band at $\lambda_{\max }=667 \mathrm{~nm}$ (Figure S6). This peak is red-shifted by $\sim 700 \mathrm{~cm}^{-1}$ relative to the same feature displayed by high-spin Cys-bound Fe'II-CDO. A red shift of similar magnitude was observed upon CN binding to SOR.(23) We also prepared rRaman samples for the Cys/CN adduct of the C93G CDO variant, which lacks the C93-Y157 cross-link (vide supra). In this case, the $S \rightarrow \mathrm{Fe}^{\text {III }} \mathrm{CT}$ band appears at $650 \mathrm{~nm}$, indicating that loss of the cross-link modulates the Fe-S bonding interaction.

rRaman spectra of the enzyme samples were obtained by $647.1 \mathrm{~nm}$ laser excitation into the $\mathrm{S} \rightarrow \mathrm{Fe}^{\text {III }} \mathrm{CT}$ band (Figure 6). In addition to the ice lattice peaks (marked by asterisks), the spectrum of WT Cys/CN-bound Fe'II-CDO exhibits two strong peaks at 377 and $429 \mathrm{~cm}^{-1}$ that are assigned to the $v(\mathrm{Fe}-\mathrm{S})$ and $v(\mathrm{Fe}-\mathrm{CN})$ stretching modes, respectively, on the basis of a comparison to the $1^{\text {ox }}-\mathrm{CN}$ results. The CDO spectrum also contains a weaker band at $495 \mathrm{~cm}^{-1}$ that is attributed to a $\delta(\mathrm{Fe}-\mathrm{C}-\mathrm{N})$ bending mode. In the rRaman spectrum of the C93G CDO variant, the $v(\mathrm{Fe}-\mathrm{S})$ - and $v(\mathrm{Fe}-\mathrm{CN})$-based peaks appear at slightly lower frequencies, which proves that the cross-link perturbs both the Cys and CN ligands. These peaks are sensitive to ${ }^{13} \mathrm{CN}$ substitution with isotope shifts similar to those observed for $\mathbf{1}^{\mathbf{0 x}}-\mathbf{C N}$ and $\mathbf{2}^{\mathbf{0 x}}-\mathbf{C N}$. 


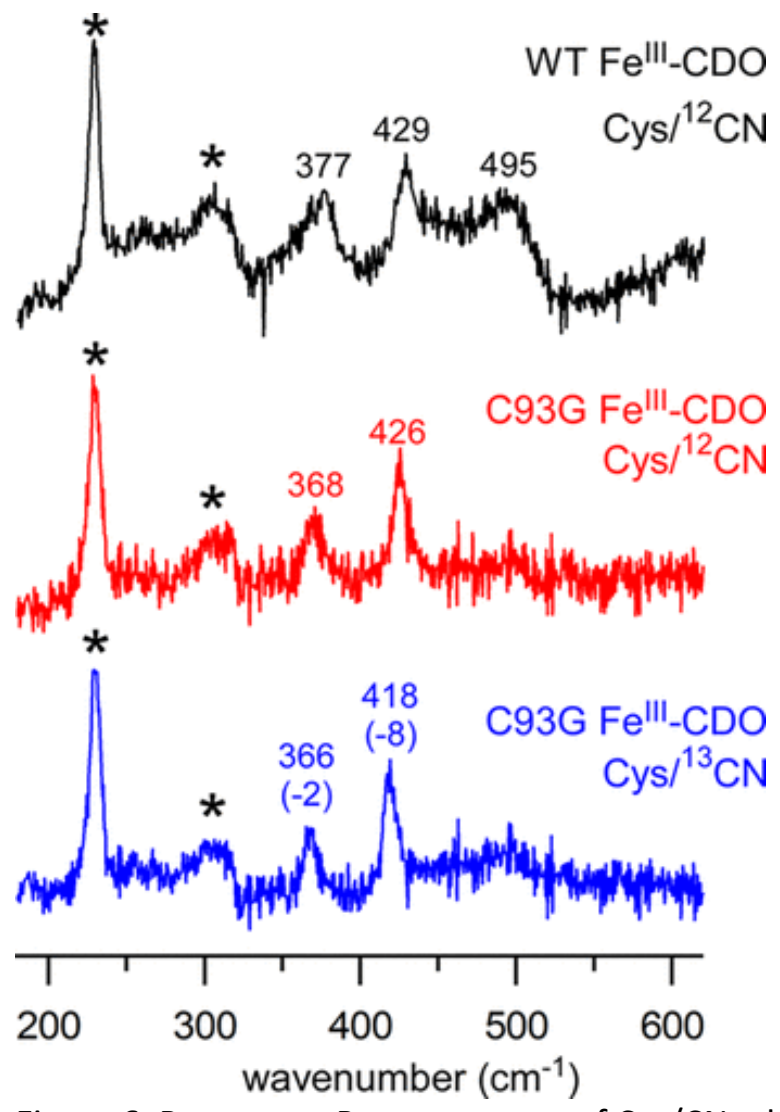

Figure 6. Resonance Raman spectra of Cys/CN adducts of CDO collected at $77 \mathrm{~K}$ using $647.1 \mathrm{~nm}$ laser excitation

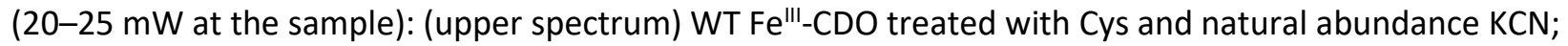

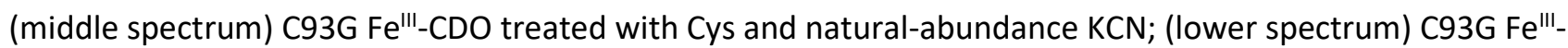
$\mathrm{CDO}$ treated with Cys and $\mathrm{K}^{13} \mathrm{C}^{14} \mathrm{~N}$. Peaks labeled with an asterisk arise from the lattice modes of ice. Frequencies and ${ }^{13} \mathrm{C}$ isotope shifts (in $\mathrm{cm}^{-1}$ ) are provided for select peaks.

The $v(\mathrm{Fe}-\mathrm{S})$ frequency of $377 \mathrm{~cm}^{-1}$ observed for the Cys/CN adduct of low-spin WT CDO is significantly higher than the value of $340 \mathrm{~cm}^{-1}$ measured for high-spin Cys-bound Fe'II-CDO.(59) This trend is opposite to that found for the synthetic complexes, as the $v(F e-S)$ frequency of low-spin $\mathbf{1}^{\text {ox }}-\mathrm{CN}$ is lower (by $36 \mathrm{~cm}^{-1}$ ) than that of highspin $\mathbf{1}^{\mathbf{0 x}}-\mathbf{N}_{\mathbf{3}}$. Interestingly, Johnson and co-workers reported that the $\mathrm{v}(\mathrm{Fe}-\mathrm{S})$ frequency of SOR is largely unchanged upon $\mathrm{CN}$ binding.(23) These findings suggest that the $v(\mathrm{Fe}-\mathrm{S})$ frequency is not a reliable indicator of spin state or Fe-S bond distance, and this issue will be addressed in greater detail in the Conclusions.

\section{Computational Studies}

\section{Geometry-Optimized Synthetic and Enzyme Models}

The geometric and electronic structures of our synthetic Fe ${ }^{\prime \prime \prime}-\mathrm{CN}$ and Fe $\mathrm{Fe}^{\mathrm{III}}-\mathrm{N}_{3}$ species were further examined with DFT calculations employing the B3LYP functional. The computational models generated via geometry optimization are shown in Figure 7, and key metric parameters are summarized in Table2 for the Fe-CN adducts. The Fe-S bond distances of 2.18 and $2.20 \AA$ computed for $\mathbf{1}^{\mathbf{0 x}}-\mathrm{CN}$ and $\mathbf{2}^{\mathrm{ox}}-\mathrm{CN}$, respectively, are significantly shorter than those measured for their Fe"l precursors, reflecting the increase in Fe oxidation state and the change from high-spin to low-spin state. In both cases, the Fe-CN units are nearly linear with $\mathrm{Fe}-\mathrm{C}-\mathrm{N}$ bond angles of $176^{\circ}$. The aryl ring of the 2-MTS ligand in $2^{\circ x}-\mathrm{CN}$ is tilted by nearly $40^{\circ}$ out of the plane created by the $\mathrm{S}-\mathrm{Fe}-\mathrm{O}$ chelate ring in order to minimize steric interactions between 2-MTS and the nearby Ph ring of ${ }^{\mathrm{Ph} 2}$ TIP. In the geometry-optimized model of $\mathbf{1}^{\mathbf{0 x}}-\mathrm{N}_{\mathbf{3}}$, the Fe- $\mathrm{N}_{3}$ unit adopts a highly bent orientation with a Fe-N-N bond angle of $136^{\circ}$. The azido ligand points away from the CysOEt chelate to avoid steric interactions with the 
adjacent phenyl rings (Figure 7). The high-spin nature of the Fe ${ }^{\text {III }}$ center in $\mathbf{1}^{\mathbf{0 x}}-\mathbf{N}_{\mathbf{3}}$ results in a lengthy Fe-S bond distance of $2.32 \AA$.

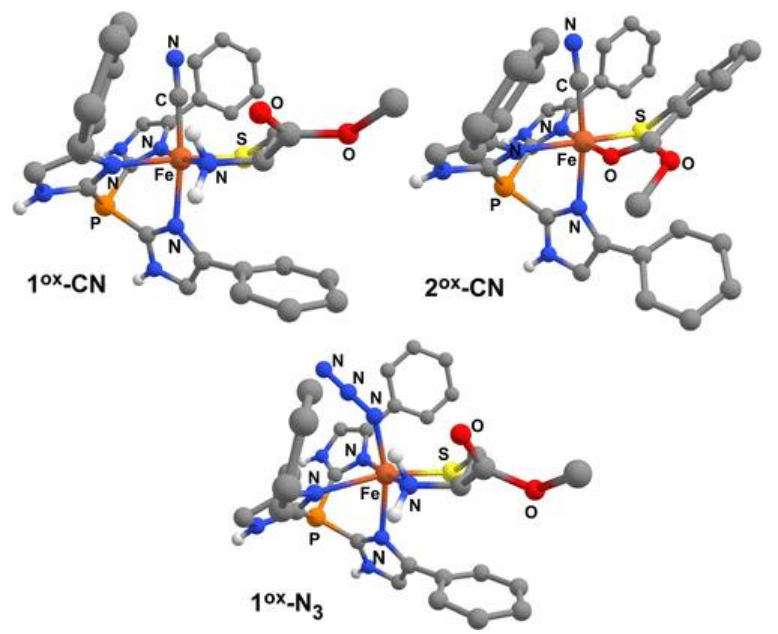

Figure 7. DFT geometry-optimized structures of $\mathbf{1}^{\mathrm{ox}}-\mathrm{CN}, \mathbf{2}^{\mathrm{ox}}-\mathrm{CN}$, and $\mathbf{1}^{\mathrm{ox}}-\mathbf{N}_{\mathbf{3}}$.

Table 2. DFT-Computed Bond Lengths ( $\AA$ ) and Angles (deg) for $1^{\mathrm{ox}}-\mathrm{CN}$ and $2^{\mathrm{ox}}-\mathrm{CN}$ Compared to Those for $\mathrm{QM} / \mathrm{MM}$-Optimized Cys/CN-Bound Fe ${ }^{\mathrm{II}}$-CDO Active Sites

\begin{tabular}{|c|c|c|c|c|c|c|}
\hline species & $\begin{array}{l}\mathrm{Fe}- \\
\mathrm{S}\end{array}$ & $\begin{array}{l}\mathrm{Fe}- \\
\mathrm{C}\end{array}$ & $\begin{array}{l}\mathrm{Fe}- \\
\mathrm{N}_{(\mathrm{His} / \mathrm{TIP})}(\mathrm{av})\end{array}$ & $\begin{array}{l}\mathrm{Fe}-\mathrm{C}- \\
\mathrm{N}\end{array}$ & $\begin{array}{l}\mathrm{N}-\mathrm{Fe}- \\
\mathrm{C}_{\mathrm{CN}}\end{array}$ & ref \\
\hline $1^{\mathrm{ox}}-\mathrm{CN}$ & 2.18 & 1.91 & 2.17 & 176.3 & 173.6 & $\begin{array}{l}\text { this } \\
\text { work }\end{array}$ \\
\hline $2^{o x}-\mathrm{CN}$ & 2.20 & 1.90 & 2.17 & 175.8 & 172.3 & $\begin{array}{l}\text { this } \\
\text { work }\end{array}$ \\
\hline (L-Cys/CN)-Fe ${ }^{\prime \prime \prime}-C D O$ cross-linked ( $\left.\alpha-C D O\right)$ & 2.28 & 1.95 & 2.07 & 169.2 & 168.6 & (30) \\
\hline $\begin{array}{l}\text { (L-Cys/CN)-Fe"'-CDO non-cross-linked ( } \beta \text { - } \\
\text { CDO) }\end{array}$ & 2.26 & 1.95 & 2.05 & 176.3 & 172.6 & (30) \\
\hline
\end{tabular}

DFT calculations of $\mathbf{1}^{\text {ox }}-\mathbf{C N}$ and $\mathbf{2}^{\text {ox }}-\mathrm{CN}$ predict $\mathrm{v}(\mathrm{Fe}-\mathrm{S})$ stretching frequencies of 378 and $365 \mathrm{~cm}^{-1}$, respectively, in reasonable agreement with the experimental data.(67) The calculations somewhat overestimate the frequencies of the $v(\mathrm{Fe}-\mathrm{CN})$ modes, providing values of 457 and $472 \mathrm{~cm}^{-1}$ for $\mathbf{1}^{\mathbf{0 x}}-\mathrm{CN}$ and $\mathbf{2}^{\mathbf{o x}}-\mathrm{CN}$, respectively. Analysis of the computed $\Delta^{13} \mathrm{C}$ isotope shifts reveals that several modes in the $420-480 \mathrm{~cm}^{-1}$ region contain partial $\delta(\mathrm{Fe}-\mathrm{C}-\mathrm{N})$ character, making it difficult to determine the precise frequencies of these modes. However, the presence of multiple isotopically active modes with $v(\mathrm{Fe}-\mathrm{CN})$ and $\delta(\mathrm{Fe}-\mathrm{C}-\mathrm{N})$ character is consistent with the rRaman data measured for the synthetic Fe ${ }^{\prime \prime \prime}-\mathrm{CN}$ adducts.

To better understand the role of outer-sphere residues in modulating the coordination geometry of the Fe center, it is worthwhile to compare the DFT-generated structures of our synthetic CDO mimics to analogous

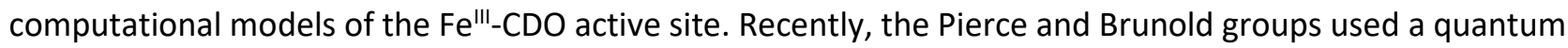

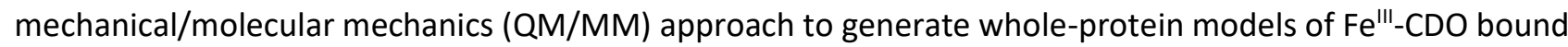
to L-Cys substrate and CN. (30) In these calculations, the QM region was treated with the same DFT/B3LYP methodology as employed here for the synthetic complexes. In the QM/MM-optimized protein structures, the carboxylate group of the L-Cys substrate forms a salt bridge to a conserved Arg60 residue, as illustrated in Figure 1. Due to this interaction, the Fe-S bond distance of $2.28 \AA$ in the CN/Cys-bound Fe'II-CDO active site is significantly longer than the value of $2.18 \AA \AA$ computed for $\mathbf{1}^{\text {ox }}$ - CN $(\underline{\text { Table2 }})$. In addition, the protein active site features shorter $\mathrm{Fe}-\mathrm{N}_{\text {His }}$ distances in comparison to the $\mathrm{Fe}-\mathrm{N}_{\mathrm{TIP}}$ distances in $\mathbf{1}^{\mathbf{o x}}-\mathbf{C N}$ and $\mathbf{2}^{\text {ox }}-\mathbf{C N}$, which contributes to the longer $\mathrm{Fe}-\mathrm{S}$ and $\mathrm{Fe}-\mathrm{C}(\mathrm{N})$ bonds in the active-site models (Table2). 
The QM/MM studies also examined the structural effects of the Cys-Tyr cross-link on the Cys/CN Fe'II-CDO adducts. Here, we adopt the labeling scheme of Pierce et al. and refer to the cross-linked and non-cross-linked enzymes as $\boldsymbol{\alpha}$-CDO and $\boldsymbol{\beta}-\mathbf{C D O}$, respectively.(27) In the absence of the cross-link, the Fe-C-N unit is nearly linear with an angle of $176^{\circ}$ (nearly identical to the values computed for $\mathbf{1}^{\mathbf{0 x}}-\mathbf{C N}$ and $\mathbf{2}^{\mathbf{o x}}-\mathbf{C N}$ ). However, $\boldsymbol{\alpha}-\mathbf{C D O}$ exhibits a more bent $\mathrm{Fe}-\mathrm{C}-\mathrm{N}$ unit with an angle of $169^{\circ}$. In addition, by shifting the position of the Tyr157 residue, the cross-link disrupts the network of hydrogen bonds between the side chain of Arg60, the phenol of Tyr157, and the substrate Cys carboxylate (Figure 1), which causes the Fe-S bond to lengthen by $0.02 \AA$. Although seemingly minor, this perturbation has a measurable effect on the electronic and spectroscopic properties of the enzyme active site, as described below.

\section{Electronic Structure and Bonding Interactions}

The DFT/B3LYP-computed molecular orbital (MO) diagram of $\mathbf{1}^{\mathbf{0 x}}-\mathrm{CN}$ shown in Figure 8a provides a useful starting point for discussing the electronic structures of these thiolate-ligated Fe $\mathrm{F}^{\text {III-CN }}$ adducts, both synthetic and enzymatic. As expected for a distorted-octahedral complex, the five $3 \mathrm{~d}$ electrons of the low-spin Fe"II center occupy the $t_{2 g}$ set of orbitals $\left(d_{x y}, d_{x z}, d_{y z}\right)$, while the $e_{g}$ orbitals $\left(d_{z}{ }^{2}, d_{x}{ }^{2}-y^{2}\right)$ are unoccupied (see Figure $8 c$ for the molecular coordinate system). The singly occupied Fe $3 \mathrm{~d}_{x y}$-based $\mathrm{MO}$ is destabilized relative to the doubly occupied Fe $3 d_{x z}$ and $3 d_{y z}$-based MOs by a strong $\pi$-antibonding interaction with the sulfur $3 p_{y}$ orbital. Following the convention established by Griffith and Taylor for low-spin Fe"ll systems, $(68,69)$ the energy difference between the $3 d_{x y}$ orbital and $3 d_{x z} / 3 d_{y z}$ pair is referred to as the tetragonal $(\Delta)$ splitting, while the gap between the $3 d_{x z} / 3 d_{y z}$ orbitals is the rhombic splitting ( $V ;$ Figure $\left.8 b\right)$. The $\Delta$ and $V$ splittings can be estimated experimentally through analysis of EPR $g$ values, as discussed in the next section.

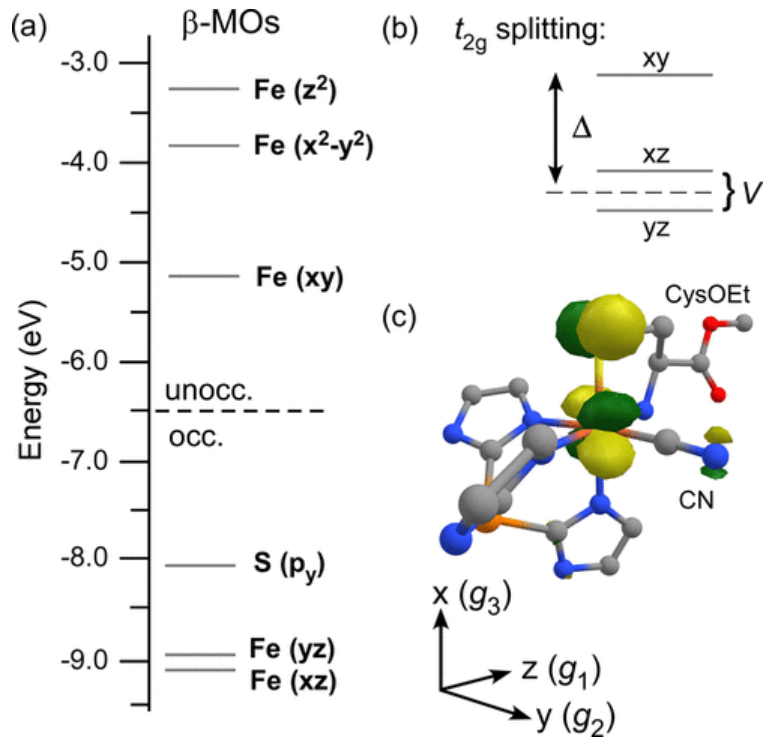

Figure 8. (a) MO diagram derived from a spin-unrestricted DFT calculation (TZVP/B3LYP) of $\mathbf{1}^{\text {ox }}$-CN. MOs are labeled according to their principal contributor, and energies correspond to the spin-down ( $\beta$ ) orbitals. (b) Schematic depiction of $\Delta$ and $V$ splittings of the $t_{2 g}$ set of Fe $3 d$ orbitals. (c) DFT-generated isosurface plot of the singly occupied natural MO of $\mathbf{1}^{\text {ox }}$-CN (phenyl rings of TIP ligand omitted for clarity).

The covalent nature of the Fe-S bond in $\mathbf{1}^{\mathbf{0 x}}-\mathbf{C N}$ is reflected in the composition of the singly occupied MO (SOMO), as determined through a natural orbital calculation based upon the DFT/B3LYP results. The SOMO of $\mathbf{1}^{\mathrm{ox}}-\mathrm{CN}$ shown in Figure $8 \mathrm{c}$ contains $75 \% \mathrm{Fe} 3 \mathrm{~d}$ and $20 \% \mathrm{~S} 3 \mathrm{p}_{y}$ character. Because of the Fe-S $\pi$-bonding interaction, the unpaired electron is partially delocalized onto the thiolate ligand, as indicated by the Mulliken spin population of 0.18 for the $S$ atom of $\mathbf{1}^{\mathbf{0 x}}-\mathbf{C N}$. The Fe-S bond of $\mathbf{2}^{\mathrm{ox}}-\mathbf{C N}$ is similarly covalent, although the thiolate-based $\pi$-donor $\mathrm{MO}$ is partially delocalized over the aromatic ring.(70) The longer Fe-S bonds of the 
enzymatic models reduce the $S$ character of the SOMOs to $14 \%$ and $11 \%$ in $\boldsymbol{\beta}$-CDO and $\boldsymbol{\alpha}$-CDO, respectively, indicative of markedly less covalent $\pi$-interactions.

\section{Computational Analysis of EPR $g$ Values}

For low-spin $\mathrm{d}^{5}$ complexes in six-coordinate environments, the anisotropy of the $\mathbf{g}$ tensor is mainly due to spinorbit coupling (SOC) among the three states arising from the parent ${ }^{2} T_{2 g}$ ground state in $O_{h}$ symmetry. However, the near-degeneracy of the ${ }^{2} T_{2 g}$-derived states poses a challenge for the calculation of magnetic and EPR properties. While coupled-perturbed self-consistent field (CP-SCF) equations are often employed to account for SOC effects in DFT calculations, previous studies (by us and others) have found that this method often fails to reproduce the $g$ values of low-spin nonheme Fe'll systems. $(30,71,72)$ Indeed, as shown in Table3, DFT/CP-SCF calculations for $\mathbf{1}^{\text {ox }}-\mathbf{C N}$ greatly underestimate the $g_{3}$ value and incorrectly predict a $g_{1}$ value greater than 2.0, regardless of the functional used. To overcome such deficiencies, we recently developed an alternative approach that utilizes time-dependent DFT to calculate the $\Delta$ and $V$ splittings (Figure $8 \mathrm{~b}$ ) of the $t_{2 g}$ orbitals.(72) These values are then entered into equations developed by Taylor to arrive at the computed $g$ values. While this strategy proved effective in predicting the $g$ values of various states of iron-type nitrile hydratase, it fails to explicitly treat metal-ligand covalency and also requires prior calibration with structurally characterized models to determine the SOC constant $(\lambda)$.

Table 3. Comparison of Computed and Experimental $g$ Values and Ligand-Field Splittings for Relevant FeCN Adducts $\underline{a}$

\begin{tabular}{|c|c|c|c|c|c|c|c|}
\hline model & method & $g_{1}$ & $g_{2}$ & $g_{3}$ & rms dev $\underline{c}$ & $\Delta\left(\mathrm{cm}^{-1}\right)$ & $V\left(\mathrm{~cm}^{-1}\right)$ \\
\hline \multirow[t]{4}{*}{$1^{\circ \times}-\mathrm{CN}$} & exptl & 1.988 & 2.161 & 2.204 & & $4731^{d}$ & $1094^{\mathrm{d}}$ \\
\hline & DFT/PBE0/CP-SCF & 2.026 & 2.127 & 2.145 & 0.045 & & \\
\hline & DFT/B3LYP/CP-SCF & 2.020 & 2.110 & 2.131 & 0.055 & & \\
\hline & CASSCF/NEVPT2 & 1.946 & 2.183 & 2.234 & 0.032 & 4321 & 512 \\
\hline \multirow[t]{2}{*}{$2^{\text {ox }}-\mathrm{CN}$} & exptl & 1.964 & 2.161 & 2.231 & & $4063^{d}$ & $1292^{d}$ \\
\hline & CASSCF/NEVPT2 & 1.953 & 2.191 & 2.256 & 0.023 & 3886 & 431 \\
\hline \multirow[t]{2}{*}{$\alpha-C D O$} & expt| $\underline{b}$ & 1.937 & 2.235 & 2.379 & & $2776^{d}$ & $1171^{\mathrm{d}}$ \\
\hline & CASSCF/NEVPT2 & 1.914 & 2.258 & 2.425 & 0.032 & 2833 & 1056 \\
\hline \multirow[t]{2}{*}{$\beta-C D O$} & exptl $\underline{b}$ & 1.951 & 2.207 & 2.344 & & $3126^{d}$ & $1416^{d}$ \\
\hline & CASSCF/NEVPT2 & 1.930 & 2.228 & 2.350 & 0.017 & 3366 & 1013 \\
\hline Hybrid-1 & CASSCF/NEVPT2 & 1.931 & 2.206 & 2.389 & nae & 3280 & 1422 \\
\hline Hybrid-2 & CASSCF/NEVPT2 & 1.971 & 2.283 & 2.352 & $n a^{e}$ & 2849 & 785 \\
\hline
\end{tabular}

${ }^{a}$ The CASSCF/NEVPT2 calculations employed a CAS $(11,13)$ active space and TZVP basis set.

${ }^{\mathrm{b}}$ Reference $(30)$.

${ }^{c}$ rms dev = root-mean-square deviation between experimental and computed $g$ values.

${ }^{\mathrm{d}}$ The experimental $\Delta$ and $V$ values were calculated using Taylor's equations for low-spin Fe ${ }^{\text {III }}$ complexes in the absence of iron-ligand covalency, assuming a SOC parameter $(\lambda)$ of $400 \mathrm{~cm}^{-1}$. See ref $\underline{(68)}$ for more details. $\mathrm{e}_{\mathrm{na}}=$ not applicable.

Neese and co-workers have demonstrated that complete active space self-consistent field (CASSCF) methods provide reliable $g$ values for transition-metal complexes, particularly when dynamic correlation is incorporated via $n$-electron valence state second-order perturbation theory (NEVPT2).(53) We therefore applied the CASSCF/NEVPT2 approach to each of the synthetic and enzymatic Fe"II-CN models described above. Initial studies gauged the impact of active-space size on the calculated $g$ values for $\mathbf{1}^{\text {ox }}-\mathbf{C N}$, starting with the minimal active space consisting of five active electrons in the five Fe $3 d$ orbitals (i.e., CAS(5,5)). As shown in Table S2, the $g$ values derived from the $\operatorname{CAS}(5,5)$ calculation $\left(g_{1,2,3}=1.932,2.272\right.$, and 2.334$)$ are significantly more 
anisotropic than the experimental values. However, improved results were obtained with the CAS $(11,8)$ active space, which includes three occupied CysOEt-based orbitals. Further addition of a second Fe $d$ shell (i.e., CAS $(11,13)$ ) yielded $g$ values in excellent agreement with experiment, as evidenced by the root-mean-square deviation of just 0.023. Expansion of the basis set (from SVP to TZVP) caused only slight changes in the computed $g$ values (Table S2), consistent with the basis-set stability of CASSCF/NEVPT2 calculations noted by Neese.(53) Analysis of the $\mathbf{g}$ tensor revealed that the $g_{1}, g_{2}$, and $g_{3}$ axes are aligned along the $\mathrm{Fe}-\mathrm{NH}_{2}, \mathrm{Fe}-\mathrm{C}_{\mathrm{CN}}$, and Fe-S bonds, respectively, as indicated in Figure 8c. Following Taylor's analysis, the average anisotropy of $g_{2}$ and $g_{3}$ (i.e., $\left(g_{2}+g_{3}\right) / 2-2.0023$ ) is dictated by $\Delta$, while the rhombicity $(V)$ accounts for the difference between $g_{2}$ and $g_{3}$.

Encouraged by our success with $\mathbf{1}^{\text {ox }}$-CN, we performed CAS(11,13)/NEVPT2 calculations for the remaining Fe ${ }^{\text {III- }}$ $\mathrm{CN}$ adducts using the TZVP basis set. In each case, the computed and experimental $g$ values are in good agreement, as indicated by root-mean-square deviations of around 0.02 (Table3). Most notably, the computational results reproduce the increased anisotropy of the enzymatic Fe"ll- $\mathrm{CN}$ adducts relative to the synthetic models, as well as the subtle differences between $\boldsymbol{\alpha}-\mathrm{CDO}$ and $\boldsymbol{\beta}-\mathrm{CDO}$. Through analysis of the ligandfield transition energies provided by the CASSCF/NEVPT2 calculations, we can extract the $\Delta$ and $V$ splittings of the $t_{2 \mathrm{~g}}$ orbitals for each model (Table3). The computed $\Delta$ values of $\mathbf{1}^{\mathbf{0 x}}-\mathbf{C N}$ and $\mathbf{2}^{\mathbf{0 x}}-\mathbf{C N}$ are 4300 and $3900 \mathrm{~cm}^{-1}$, respectively, reflecting the considerable destabilization of the $\mathrm{Fe} 3 \mathrm{~d}_{x y}$-based $\mathrm{MO}$ due to $\pi$-antibonding interactions with the thiolate donor (vide supra). In comparison, the $\Delta$ values of $\boldsymbol{\alpha}$-CDO and $\boldsymbol{\beta}$-CDO are smaller by roughly $1000 \mathrm{~cm}^{-1}$, which increases the $\mathrm{g}$ tensor anisotropy by enhancing SOC-induced mixing among the ${ }^{2} \mathrm{~T}_{2 \mathrm{~g}}$ derived states. The decrease in $\Delta$ is largely a consequence of the elongated Fe-S bonds in $\boldsymbol{\alpha}-\mathrm{CDO}$ and $\boldsymbol{\beta}$ CDO relative to the synthetic complexes (Table2). The computed $V$ splittings are also greater for the enzymatic structures, although the experimentally determined rhombicities are roughly similar for both the synthetic and biological Fe"II-CN adducts.

The CASSCF/NEVPT2 calculations help to illuminate the structural origins of the different $g$ values exhibited by $\alpha$ CDO and $\boldsymbol{\beta}$-CDO. As described above, the presence of the Cys-Tyr cross-link lengthens the Fe-S bond and induces a decrease in the $\mathrm{Fe}-\mathrm{C}-\mathrm{N}$ bond angle. To determine whether these perturbations are responsible for the greater $g$ anisotropy of $\boldsymbol{\alpha}$-CDO, we generated two hybrid structures. Hybrid-1 is identical with $\boldsymbol{\beta}$-CDO apart from the Fe-CN unit, which adopts the bent orientation of $\alpha-\mathrm{CDO}$ ( $\mathrm{Fe}-\mathrm{C}-\mathrm{N}$ angle of $\left.169^{\circ}\right)$. In the Hybrid-2 structure, the Fe-CN unit is nearly linear as in $\beta-\mathrm{CDO}$ ( $\mathrm{Fe}-\mathrm{C}-\mathrm{N}$ angle of $176^{\circ}$ ) but the $\mathrm{Fe}-\mathrm{S}_{\mathrm{cys}}$ and $\mathrm{Fe}-\mathrm{N}_{\text {cys }}$ bond distances correspond to those found in $\boldsymbol{\alpha}-\mathrm{CDO}$. As shown in $\underline{\mathrm{Table} 3}$, the $\Delta$ value is primarily determined by the length of the Fe-S bond, while the Fe-C $-\mathrm{N}$ bond angle has the greatest effect on the rhombicity parameter ( $V$ ). Comparison of the computed $g$ values indicates that the larger $g_{3}$ value of $\boldsymbol{\alpha}$-CDO-in comparison to $\boldsymbol{\beta}$-CDO-is mainly a consequence of the bend in the FeCN unit due to the Cys-Tyr cross-link. The $g_{2}$ value is most sensitive to the Fe-S bond distance, while the effect of structural variations on $g_{1}$ is less clear. These results support the conclusion that the observed shifts in $g$ values between $\alpha-C D O$ and $\beta-C D O$ arise from cross-linked-induced perturbations of both the $\mathrm{CN}$ and Cys ligands.

\section{Conclusions}

A variety of synthetic, spectroscopic, and computational methods have been used to elucidate the geometric and electronic structures of thiolate-ligated Fe"l' complexes of relevance to the active sites of thiol dioxygenases. These efforts included the preparation and structural characterization of [Fe" (2-MTS)( $\left.\left.{ }^{\mathrm{Ph} 2} \mathrm{TIP}\right)\right] \mathrm{BPh}_{4}(\mathbf{2})$, which serves as the first synthetic model of substrate-bound Fe"-MDO (Figure 2). One-electron chemical oxidation of $\mathbf{2}$ and the previously reported $\mathbf{1}$ yielded ferric derivatives capable of binding small anions (namely, cyanide and azide) that are commonly used as spectroscopic probes of biological and synthetic Fe sites involved in $\mathrm{O}_{2}$ activation. The formation of six-coordinate Fe"III-CN and Fe" $-\mathrm{N}_{3}$ adducts $\left(\mathbf{1}^{\mathrm{ox}}-\mathrm{CN}, \mathbf{2}^{\mathbf{o x}}-\mathbf{C N}\right.$, and $\left.\mathbf{1}^{\mathbf{o x}}-\mathbf{N}_{3}\right)$ was confirmed by examination with UV-vis absorption, EPR, and rRaman spectroscopies. DFT calculations 
determined that the unpaired electron of the Fe ${ }^{\prime \prime \prime}-\mathrm{CN}$ complexes occupies the Fe $3 \mathrm{~d}_{x y}$-based $\mathrm{MO}$ that carries significant $S$ character due to the covalent nature of the Fe-S $\pi$-bond. In addition, the $g$ values derived from CASSCF/NEVPT2 calculations for $\mathbf{1}^{\text {ox }}-\mathbf{C N}$ and $\mathbf{2}^{\text {ox }}-\mathbf{C N}$ are in excellent agreement with the experimental data. The observed and calculated $\mathbf{g}$ tensors were rationalized on the basis of $\Delta$ and $V$ splittings among the Fe $3 d$ $t_{2 g}$ orbitals.

Importantly, our studies of the synthetic CDO/MDO models facilitated the interpretation of data collected in parallel studies of CDO. We expanded upon the prior EPR studies of Pierce and co-workers by collecting rRaman spectra of Cys- and CN-bound Fe ${ }^{\prime \prime \prime}-\mathrm{CDO}$. The assignment of $\mathrm{v}(\mathrm{Fe}-\mathrm{S}), \mathrm{v}(\mathrm{Fe}-\mathrm{CN})$, and $\delta(\mathrm{Fe}-\mathrm{C}-\mathrm{N})$ features in the rRaman spectra was aided by close similarities between the enzymatic and model spectra. The effect of the CysTyr cross-link was examined by comparing rRaman spectra of Cys- and CN-treated WT CDO (cross-linked; $\boldsymbol{\alpha}$-CDO) and C93G CDO (non-cross-linked; $\boldsymbol{\beta}-\mathrm{CDO})$. Small shifts in the $v(\mathrm{Fe}-\mathrm{S})$ and $v(\mathrm{Fe}-\mathrm{CN})$ frequencies indicate that both the $\mathrm{CN}$ and $\mathrm{Cys}$ ligands are perturbed by formation of the cross-link. This finding is consistent with prior QM/MM calculations which provided the active site models that we used in our ab initio computational studies of CDO

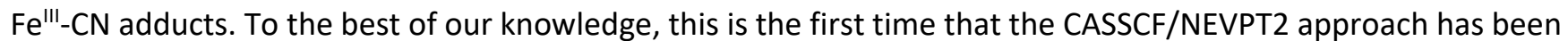
applied to a metalloenzyme active site. The computed $g$ values for $\boldsymbol{\alpha}$-CDO and $\boldsymbol{\beta}$-CDO exhibit remarkably good agreement with experiment. Moreover, by analyzing the effect of structural variations on the computed $g$ values and ligand-field splittings, we determined that the greater $g$ anisotropy of $\boldsymbol{\alpha}$-CDO-in comparison to $\boldsymbol{\beta}$-CDO-is the result of both the elongation of the Fe-S bond and the tilting of the Fe- $\mathrm{CN}$ unit caused by the Cys-Tyr crosslink.

It is somewhat curious that loss of the Cys-Tyr cross-link is accompanied by a slight decrease $\left(9 \mathrm{~cm}^{-1}\right)$ in the $v(\mathrm{Fe}-$ S) frequency of Cys- and CN-bound Fe ${ }^{\prime \prime \prime}-\mathrm{CDO}$ (Figure 6), even though the computational results indicate that the $\mathrm{Fe}-\mathrm{S}$ bond is shorter in the non-cross-linked active site. This finding would seem to contradict Badger's rule, which states that bond length is inversely proportional to vibrational frequency. $(73,74)$ We noted a similar discrepancy in our studies of the synthetic adducts: the $v(F e-S)$ frequency of $\mathbf{1}^{\text {ox }}-\mathbf{C N}\left(341 \mathrm{~cm}^{-1}\right)$ is lower than that of $\mathbf{1}^{\text {ox }}-\mathrm{N}_{3}\left(377 \mathrm{~cm}^{-1}\right)$, even though DFT calculations provide Fe-S bond distances of 2.18 and $2.32 \AA$, respectively.

To explore this matter further, we sought to compare the spin states, $v(\mathrm{Fe}-\mathrm{S})$ frequencies, and computed Fe-S bond distances of biological and synthetic nonheme Fe ${ }^{\text {III }}$ centers with mixed $\mathrm{S} / \mathrm{N}$ coordination reported in the literature. From the data compiled in Table4, and the corresponding plots in Figure S7, it is clear that the v(Fe-S) modes of these nonheme iron sites do not behave according to Badger's rule. To determine whether the lack of a clear relationship could be due to errors in the calculated Fe-S bonds, we performed geometry optimizations of $\mathbf{1}^{\text {ox }}$-CN and $\mathbf{2}^{\text {ox }}$-CN using a range of DFT functionals (nonhybrid, meta-GGA, and hybrid). As shown in Table S3, the absolute and relative Fe-S bond distances are largely independent of functional, suggesting that differences in computational methods cannot entirely account for the observed breakdown in Badger's rule. Another likely explanation is that the Fe-S stretching motion is often strongly coupled to $\delta(\mathrm{S}-\mathrm{C}-\mathrm{C})$ and $\delta(\mathrm{C}-\mathrm{C}-\mathrm{N})$ motions, and thus $v(\mathrm{Fe}-\mathrm{S})$ character is distributed across several modes. Because of this, the $v(\mathrm{Fe}-\mathrm{S})$ frequency is not a dependable marker of either spin state or Fe-S bond distance in nonheme iron systems. In contrast, our results suggest that EPR studies of low-spin Fe ${ }^{\text {III }}$ sites can provide more reliable structural insights when they are conducted in tandem with DFT and CASSCF/NEVPT2 calculations.

Table 4. Spin States, Fe-S Bond Distances, and Fe-S Stretching Frequencies of Nonheme Fe ${ }^{\text {III }}$ Centers with Mixed $\mathrm{S} / \mathrm{N}$ Ligation

\begin{tabular}{|c|c|c|c|c|}
\hline & spin & $r(\mathrm{Fe}-\mathrm{S}), \mathrm{A} a \underline{a}$ & $\mathrm{v}(\mathrm{Fe}-\mathrm{S}), \mathrm{cm}^{-1}$ & ref \\
\hline \multicolumn{5}{|c|}{ Synthetic } \\
\hline $1^{\text {ox }}-\mathrm{CN}$ & $1 / 2$ & 2.18 & 341 & this work \\
\hline $2^{\circ x}-\mathrm{CN}$ & $1 / 2$ & 2.20 & 347 & this work \\
\hline $1^{\circ x}-N_{3}$ & $5 / 2$ & 2.32 & 377 & this work \\
\hline
\end{tabular}




\begin{tabular}{|c|c|c|c|c|}
\hline [Fe"'(cyclam-PrS)(OOH)] $^{+}$ & $5 / 2$ & 2.36 & 352 & (61) \\
\hline \multicolumn{5}{|l|}{ Biological } \\
\hline Cys-bound WT Fe'"'-CDO & $5 / 2$ & 2.27 & 340 & (59) \\
\hline Cys/CN-bound Fe"l'-CDO (WT) & $1 / 2$ & 2.28 & 377 & (30) \\
\hline Cys/CN-bound Fe"l'-CDO (C93G) & $1 / 2$ & 2.26 & 368 & (30) \\
\hline Fe"'-SOR & $5 / 2$ & $2.36^{\underline{b}}$ & 323 & (58) \\
\hline CN-bound Fe"'-SOR & $1 / 2$ & 2.28 & 323 & (23) \\
\hline nitrile hydratase (low pH form) & $1 / 2$ & $2.21 \subseteq$ & 373 & (65) \\
\hline
\end{tabular}

aUnless otherwise noted, the Fe-S bond distances are derived from theoretical calculations.

${ }^{b}$ Bond distance determined from EXAFS analysis (ref (75)).

'Bond distance determined from EXAFS analysis (ref (76)).

\section{Supporting Information}

The Supporting Information is available free of charge at https://pubs.acs.org/doi/10.1021/acs.inorgchem.9b02432.

${ }^{1} \mathrm{H}$ NMR spectra of $\mathbf{2}$, EPR spectra of $\mathbf{1}^{\mathrm{ox}}$ and $\mathbf{2}^{\mathrm{ox}}$, rRaman spectra of $\mathbf{1}^{\mathbf{0 x}}-\mathbf{N}_{\mathbf{3}}$, UV-vis spectra of Cys/CN adducts of $\mathrm{Fe}^{\mathrm{III}}-\mathrm{CDO}$, plots of Fe-S bond distances versus stretching frequencies, metric parameters determined by $\mathrm{X}$-ray crystallography, CASSCF/NEVTP2 computed $g$ values for $\mathbf{1}^{\mathrm{ox}}-\mathrm{CN}$, and coordinates for computational structures (PDF)

Pdf ic9b02432 si 001.pdf (2.22 MB)

\section{Accession Codes}

CCDC 1945809 contains the supplementary crystallographic data for this paper. These data can be obtained free of charge via www.ccdc.cam.ac.uk/data request/cif, or by emailing data request@ccdc.cam.ac.uk, or by contacting The Cambridge Crystallographic Data Centre, 12 Union Road, Cambridge CB2 1EZ, UK; fax: +44 1223 336033.

The authors declare no competing financial interest.

\section{Terms \& Conditions}

Electronic Supporting Information files are available without a subscription to ACS Web Editions. The American Chemical Society holds a copyright ownership interest in any copyrightable Supporting Information. Files available from the ACS website may be downloaded for personal use only. Users are not otherwise permitted to reproduce, republish, redistribute, or sell any Supporting Information from the ACS website, either in whole or in part, in either machine-readable form or any other form without permission from the American Chemical Society. For permission to reproduce, republish and redistribute this material, requesters must process their own requests via the RightsLink permission system. Information about how to use the RightsLink permission system can be found at http://pubs.acs.org/page/copyright/permissions.html.

\section{Acknowledgments}

The authors are grateful for financial support from the National Institutes of Health (GM126522 to A.T.F. and GM117120 to T.C.B.). Initial funding for this project was provided by the National Science Foundation (CHE1056845 to A.T.F.). Improvements to the X-band EPR instrument at Marquette University were funded through a grant from the National Science Foundation (CHE-1532168). 


\section{References}

1 Stipanuk, M. H.; Simmons, C. R.; Andrew Karplus, P.; Dominy, J. E., Jr. Thiol dioxygenases: unique families of cupin proteins. Amino Acids 2011, 41, 91-102, DOI: 10.1007/s00726-010-0518-2

$\underline{2}$ Stipanuk, M. H.; Londono, M.; Hirschberger, L. L.; Hickey, C.; Thiel, D. J.; Wang, L. Evidence for expression of a single distinct form of mammalian cysteine dioxygenase. Amino Acids 2004, 26, 99-106, DOI: 10.1007/s00726-003-0001-4

3 Stipanuk, M. H. Sulfur amino acid metabolism: Pathways for production and removal of homocysteine and cysteine. Annu. Rev. Nutr. 2004, 24, 539- 577, DOI: 10.1146/annurev.nutr.24.012003.132418

$\underline{4}$ Chai, S. C.; Jerkins, A. A.; Banik, J. J.; Shalev, I.; Pinkham, J. L.; Uden, P. C.; Maroney, M. J. Heterologous expression, purification, and characterization of recombinant rat cysteine dioxygenase. J. Biol. Chem. 2005, 280, 9865- 9869, DOI: 10.1074/jbc.M413733200

$\underline{5}$ Dominy, J. E., Jr.; Simmons, C. R.; Hirschberger, L. L.; Hwang, J.; Coloso, R. M.; Stipanuk, M. H. Discovery and Characterization of a Second Mammalian Thiol Dioxygenase, Cysteamine Dioxygenase. J. Biol. Chem. 2007, 282, 25189- 25198, DOI: 10.1074/jbc.M703089200

6 Masson, N.; Keeley, T. P.; Giuntoli, B.; White, M. D.; Puerta, M. L.; Perata, P.; Hopkinson, R. J.; Flashman, E.; Licausi, F.; Ratcliffe, P. J. Conserved N-terminal cysteine dioxygenases transduce responses to hypoxia in animals and plants. Science 2019, 365, 65-69, DOI: 10.1126/science.aaw0112

7 Dominy, J. E., Jr.; Simmons, C. R.; Karplus, P. A.; Gehring, A. M.; Stipanuk, M. H. Identification and characterization of bacterial cysteine dioxygenases: a new route of cysteine degradation for eubacteria. J. Bacteriol. 2006, 188, 5561- 5569, DOI: 10.1128/JB.00291-06

$\underline{8}$ Driggers, C. M.; Hartman, S. J.; Karplus, P. A. Structures of Arg- and Gln-type bacterial cysteine dioxygenase homologs. Protein Sci. 2015, 24, 154-161, DOI: 10.1002/pro.2587

9 Bruland, N.; Wuebbeler, J. H.; Steinbuechel, A. 3-Mercaptopropionate dioxygenase, a cysteine dioxygenase homolog, catalyzes the initial step of 3-mercaptopropionate catabolism in the 3,3-thiodipropionic aciddegrading bacterium Variovorax paradoxus. J. Biol. Chem. 2009, 284, 660-672, DOI: 10.1074/jbc.M806762200

10 Pierce, B. S.; Subedi, B. P.; Sardar, S.; Crowell, J. K. The "Gln-Type" Thiol Dioxygenase from Azotobacter vinelandii Is a 3-Mercaptopropionic Acid Dioxygenase. Biochemistry 2015, 54, 7477- 7490, DOI: 10.1021/acs.biochem.5b00636

$\underline{11}$ Tchesnokov, E. P.; Fellner, M.; Siakkou, E.; Kleffmann, T.; Martin, L. W.; Aloi, S.; Lamont, I. L.; Wilbanks, S. M.; Jameson, G. N. L. The Cysteine Dioxygenase Homologue from Pseudomonas aeruginosa Is a 3Mercaptopropionate Dioxygenase. J. Biol. Chem. 2015, 290, 24424-24437, DOI: 10.1074/jbc.M114.635672

12 Driggers, C. M.; Cooley, R. B.; Sankaran, B.; Hirschberger, L. L.; Stipanuk, M. H.; Karplus, P. A. Cysteine Dioxygenase Structures from pH 4 to 9: Consistent Cys-Persulfenate Formation at Intermediate $\mathrm{pH}$ and a Cys-Bound Enzyme at Higher pH. J. Mol. Biol. 2013, 425, 3121-3136, DOI: 10.1016/j.jmb.2013.05.028

13 Driggers, C. M.; Kean, K. M.; Hirschberger, L. L.; Cooley, R. B.; Stipanuk, M. H.; Karplus, P. A. Structure-Based Insights into the Role of the Cys-Tyr Crosslink and Inhibitor Recognition by Mammalian Cysteine Dioxygenase. J. Mol. Biol. 2016, 428, 3999-4012, DOI: 10.1016/j.jmb.2016.07.012

14 McCoy, J. G.; Bailey, L. J.; Bitto, E.; Bingman, C. A.; Aceti, D. J.; Fox, B. G.; Phillips, G. N., Jr Structure and mechanism of mouse cysteine dioxygenase. Proc. Natl. Acad. Sci. U. S. A. 2006, 103, 3084-3089, DOI: 10.1073/pnas.0509262103

15 Wang, Y.; Griffith, W. P.; Li, J.; Koto, T.; Wherritt, D. J.; Fritz, E.; Liu, A. Cofactor Biogenesis in Cysteamine Dioxygenase: C-F Bond Cleavage with Genetically Incorporated Unnatural Tyrosine. Angew. Chem., Int. Ed. 2018, 57, 8149, DOI: 10.1002/anie.201803907 
16 Aloi, S.; Davies, C. G.; Karplus, P. A.; Wilbanks, S. M.; Jameson, G. N. L. Substrate specificity in thiol dioxygenases. Biochemistry 2019, 58, 2398-2407, DOI: 10.1021/acs.biochem.9b00079

17 Dominy, J. E., Jr.; Hwang, J.; Guo, S.; Hirschberger, L. L.; Zhang, S.; Stipanuk, M. H. Synthesis of Amino Acid Cofactor in Cysteine Dioxygenase Is Regulated by Substrate and Represents a Novel Post-translational Regulation of Activity. J. Biol. Chem. 2008, 283, 12188-12201, DOI: 10.1074/jbc.M800044200

18 Wang, Y.; Griffith, W. P.; Li, J.; Koto, T.; Wherritt, D. J.; Fritz, E.; Liu, A. Cofactor Biogenesis in Cysteamine Dioxygenase: C-F Bond Cleavage with Genetically Incorporated Unnatural Tyrosine. Angew. Chem., Int. Ed. 2018, 57, 8149-8153, DOI: 10.1002/anie.201803907

19 Li, J.; Griffith, W. P.; Davis, I.; Shin, I.; Wang, J.; Li, F.; Wang, Y.; Wherritt, D. J.; Liu, A. Cleavage of a carbonfluorine bond by an engineered cysteine dioxygenase. Nat. Chem. Biol. 2018, 14, 853-860, DOI: 10.1038/s41589-018-0085-5

$\underline{20}$ Ye, S.; Wu, X. a.; Wei, L.; Tang, D.; Sun, P.; Bartlam, M.; Rao, Z. An Insight into the Mechanism of Human Cysteine Dioxygenase. Key Roles of the Thioether-Bonded Tyrosine-Cysteine Cofactor. J. Biol. Chem. 2007, 282, 3391-3402, DOI: 10.1074/jbc.M609337200

$\underline{21}$ Crowell, J. K.; Sardar, S.; Hossain, M. S.; Foss, F. W., Jr.; Pierce, B. S. Non-chemical proton-dependent steps prior to $\mathrm{O}_{2}$-activation limit Azotobacter vinelandii 3-mercaptopropionic acid dioxygenase (MDO) catalysis. Arch. Biochem. Biophys. 2016, 604, 86-94, DOI: 10.1016/j.abb.2016.06.009

$\underline{22} \mathrm{Li}, \mathrm{W}$.; Pierce, B. S. Steady-state substrate specificity and $\mathrm{O}_{2}$-coupling efficiency of mouse cysteine dioxygenase. Arch. Biochem. Biophys. 2015, 565, 49- 56, DOI: 10.1016/j.abb.2014.11.004

23 Clay, M. D.; Yang, T.-C.; Jenney, F. E., Jr.; Kung, I. Y.; Cosper, C. A.; Krishnan, R.; Kurtz, D. M., Jr.; Adams, M. W. W.; Hoffman, B. M.; Johnson, M. K. Geometries and Electronic Structures of Cyanide Adducts of the Non-Heme Iron Active Site of Superoxide Reductases: Vibrational and ENDOR Studies. Biochemistry 2006, 45, 427-438, DOI: 10.1021/bi052034v

$\underline{\mathbf{2 4}}$ Clay, M. D.; Cosper, C. A.; Jenney, F. E., Jr.; Adams, M. W. W.; Johnson, M. K. Nitric oxide binding at the mononuclear active site of reduced pyrococcus furiosus superoxide reductase. Proc. Natl. Acad. Sci. U. S. A. 2003, 100, 3796-3801, DOI: 10.1073/pnas.0636858100

$\underline{\mathbf{2 5}}$ Simianu, M. C.; Kincaid, J. R. Resonance Raman Spectroscopic Detection of Both Linear and Bent Fe-CN Fragments for the Cyanide Adducts of Cytochrome P-450 Camphor and Its Substrate-Bound Forms. Relevance to the "Charge Relay" Mechanism. J. Am. Chem. Soc. 1995, 117, 4628- 36, DOI: 10.1021/ja00121a020

$\underline{26}$ Jackson, T. A.; Karapetian, A.; Miller, A.-F.; Brunold, T. C. Probing the Geometric and Electronic Structures of the Low-Temperature Azide Adduct and the Product-Inhibited Form of Oxidized Manganese Superoxide Dismutase. Biochemistry 2005, 44, 1504-1520, DOI: 10.1021/bi048639t

$\underline{27}$ Pierce, B. S.; Gardner, J. D.; Bailey, L. J.; Brunold, T. C.; Fox, B. G. Characterization of the nitrosyl adduct of substrate-bound mouse cysteine dioxygenase by electron paramagnetic resonance: Electronic structure of the active site and mechanistic implications. Biochemistry 2007, 46, 8569-8578, DOI: 10.1021/bi700662d

$\underline{\mathbf{2 8}} \mathrm{Li}$, J.; Koto, T.; Davis, I.; Liu, A. Probing the Cys-Tyr Cofactor Biogenesis in Cysteine Dioxygenase by the Genetic Incorporation of Fluorotyrosine. Biochemistry 2019, 58, 2218- 2227, DOI: 10.1021/acs.biochem.9b00006

$\underline{29}$ Blaesi, E. J.; Fox, B. G.; Brunold, T. C. Spectroscopic and Computational Investigation of Iron(III) Cysteine Dioxygenase: Implications for the Nature of the Putative Superoxo-Fe(III) Intermediate. Biochemistry 2014, 53, 5759- 5770, DOI: 10.1021/bi500767x

30 Li, W.; Blaesi, E. J.; Pecore, M. D.; Crowell, J. K.; Pierce, B. S. Second-sphere interactions between the C93Y157 crosslink and the substrate-bound Fe site influence the $\mathrm{O}_{2}$ coupling efficiency in mouse cysteine dioxygenase. Biochemistry 2013, 52, 9104-9119, DOI: 10.1021/bi4010232 
$\underline{31}$ Fischer, A. A.; Stracey, N.; Lindeman, S. V.; Brunold, T. C.; Fiedler, A. T. Synthesis, x-ray structures, electronic properties, and $\mathrm{O} 2 / \mathrm{NO}$ reactivities of thiol dioxygenase active-site models. Inorg.

Chem. 2016, 55, 11839-11853, DOI: 10.1021/acs.inorgchem.6b01931

32 McQuilken, A. C.; Jiang, Y.; Siegler, M. A.; Goldberg, D. P. Addition of Dioxygen to an N4S(thiolate) Iron(II) Cysteine Dioxygenase Model Gives a Structurally Characterized Sulfinato-Iron(II) Complex. J. Am. Chem. Soc. 2012, 134, 8758-8761, DOI: 10.1021/ja302112y

33 McQuilken, A. C.; Ha, Y.; Sutherlin, K. D.; Siegler, M. A.; Hodgson, K. O.; Hedman, B.; Solomon, E. I.; Jameson, G. N. L.; Goldberg, D. P. Preparation of Non-heme \{FeNO\}7 Models of Cysteine Dioxygenase: Sulfur versus Nitrogen Ligation and Photorelease of Nitric Oxide. J. Am. Chem.

Soc. 2013, 135, 14024- 14027, DOI: 10.1021/ja4064487

34 McQuilken, A. C.; Goldberg, D. P. Sulfur oxygenation in biomimetic non-heme iron-thiolate complexes. Dalton Trans. 2012, 41, 10883-10899, DOI: 10.1039/c2dt30806a

35 Blakely, M. N.; Dedushko, M. A.; Poon, P. C. Y.; Villar-Acevedo, G.; Kovacs, J. A. Formation of a Reactive, Alkyl Thiolate-Ligated FellI-Superoxo Intermediate Derived from Dioxygen. J. Am. Chem.

Soc. 2019, 141, 1867- 1870, DOI: 10.1021/jacs.8b12670

36 Bittner, M. M.; Baus, J. S.; Lindeman, S. V.; Fiedler, A. T. Synthesis and Structural Characterization of Iron(II) Complexes with Tris(imidazolyl)phosphane Ligands: A Platform for Modeling the 3-Histidine Facial Triad of Nonheme Iron Dioxygenases. Eur. J. Inorg. Chem. 2012, 2012, 1848-1856, DOI:

10.1002/ejic.201101282

37 Blaesi, E. J.; Fox, B. G.; Brunold, T. C. Spectroscopic and computational Investigation of the H155A variant of cysteine dioxygenase: Geometric and electronic consequences of a third-sphere amino acid substitution. Biochemistry 2015, 54, 2874- 2884, DOI: 10.1021/acs.biochem.5b00171

38 Blaesi, E. J.; Gardner, J. D.; Fox, B. G.; Brunold, T. C. Spectroscopic and computational characterization of the $\mathrm{NO}$ adduct of substrate-bound $\mathrm{Fe}(\mathrm{II})$ cysteine dioxygenase: Insights into the mechanism of $\mathrm{O} 2$ activation. Biochemistry 2013, 52, 6040-6051, DOI: 10.1021/bi400825c

39 Fischer, D. S.; Price, D. C. Simple serum iron method using the new sensitive chromogen tripyridyl-striazine. Clin. Chem. 1964, 10, 21- 31

40 Stoll, S.; Schweiger, A. EasySpin, a comprehensive software package for spectral simulation and analysis in EPR. J. Magn. Reson. 2006, 178, 42- 55, DOI: 10.1016/j.jmr.2005.08.013

41 Neese, F. ORCA - An Ab Initio, DFT and Semiempirical Electronic Structure Package, versions 3.0 and 4.0; Max Planck Institute for Chemical Energy Conversion: Muelheim, Germany, 2017.

42 Becke, A. D. Density-Functional Thermochemistry. 3. The Role of Exact Exchange. J. Chem. Phys. 1993, 98, 5648- 5652, DOI: 10.1063/1.464913

43 Lee, C. T.; Yang, W. T.; Parr, R. G. Development of the Colle-Salvetti Correlation-Energy Formula into a Functional of the Electron-Density. Phys. Rev. B: Condens. Matter Mater. Phys. 1988, 37, 785- 789, DOI: 10.1103/PhysRevB.37.785

44 Schafer, A.; Huber, C.; Ahlrichs, R. Fully Optimized Contracted Gaussian-Basis Sets of Triple Zeta Valence Quality for Atoms Li to Kr. J. Chem. Phys. 1994, 100, 5829- 5835, DOI: 10.1063/1.467146

45 Schafer, A.; Horn, H.; Ahlrichs, R. Fully Optimized Contracted Gaussian-Basis Sets for Atoms Li to Kr. J. Chem. Phys. 1992, 97, 2571- 2577, DOI: 10.1063/1.463096

46 Weigend, F.; Ahlrichs, R. Balanced basis sets of split valence, triple zeta valence and quadruple zeta valence quality for $\mathrm{H}$ to Rn: Design and assessment of accuracy. Phys. Chem. Chem.

Phys. 2005, 7, 3297-3305, DOI: 10.1039/b508541a

47 Neese, F.; Wennmohs, F.; Hansen, A.; Becker, U. Efficient, approximate and parallel Hartree-Fock and hybrid DFT calculations. A 'chain-of-spheres' algorithm for the Hartree-Fock exchange. Chem.

Phys. 2009, 356, 98-109, DOI: 10.1016/j.chemphys.2008.10.036 
48 Eichkorn, K.; Treutler, O.; Oehm, H.; Haeser, M.; Ahlrichs, R. Auxiliary basis sets to approximate Coulomb potentials. Chem. Phys. Lett. 1995, 240, 283-290, DOI: 10.1016/0009-2614(95)00621-A

49 Neese, F. Quantum chemical calculations of spectroscopic properties of metalloproteins and model compounds: EPR and Moessbauer properties. Curr. Opin. Chem. Biol. 2003, 7, 125-135, DOI: 10.1016/S1367-5931(02)00006-6

50 Neese, F. Prediction of electron paramagnetic resonance $g$ values using coupled perturbed Hartree-Fock and Kohn-Sham theory. J. Chem. Phys. 2001, 115, 11080- 11096, DOI: 10.1063/1.1419058

$\underline{51}$ Sinnecker, S.; Neese, F.; Noodleman, L.; Lubitz, W. Calculating the electron paramagnetic resonance parameters of exchange coupled transition metal complexes using broken symmetry density functional theory: Application to a Mn(III)/Mn(IV) model compound. J. Am. Chem. Soc. 2004, 126, 2613-2622, DOI: 10.1021/ja0390202

$\underline{\mathbf{5 2}}$ Neese, F. Metal and ligand hyperfine couplings in transition metal complexes: the effect of spin-orbit coupling as studied by coupled perturbed Kohn-Sham theory. J. Chem.

Phys. 2003, 118, 3939- 3948, DOI: 10.1063/1.1540619

53 Singh, S. K.; Atanasov, M.; Neese, F. Challenges in Multireference Perturbation Theory for the Calculations of the g-Tensor of First-Row Transition-Metal Complexes. J. Chem. Theory Comput. 2018, 14, 4662-4677, DOI: 10.1021/acs.jctc.8b00513

54 Singh, S. K.; Eng, J.; Atanasov, M.; Neese, F. Covalency and chemical bonding in transition metal complexes: An ab initio based ligand field perspective. Coord. Chem. Rev. 2017, 344, 2- 25, DOI: 10.1016/j.ccr.2017.03.018

$\underline{55}$ Addison, A. W.; Rao, T. N.; Reedijk, J.; Vanrijn, J.; Verschoor, G. C. Synthesis, Structure, and Spectroscopic Properties of Copper(II) Compounds Containing Nitrogen Sulfur Donor Ligands. J. Chem. Soc., Dalton Trans. 1984, 1349-1356, DOI: 10.1039/DT9840001349

56 Connelly, N. G.; Geiger, W. E. Chemical Redox Agents for Organometallic Chemistry. Chem. Rev. 1996, 96, 877-910, DOI: 10.1021/cr940053x

57 Gutman, C. T.; Guzei, I. A.; Brunold, T. C. Structural, Spectroscopic, and Computational Characterization of the Azide Adduct of FellI(2,6-diacetylpyridinebis(semioxamazide)), a Functional Analogue of Iron Superoxide Dismutase. Inorg. Chem. 2013, 52, 8909-8918, DOI: 10.1021/ic401098x

58 Clay, M. D.; Jenney, F. E., Jr.; Noh, H. J.; Hagedoorn, P. L.; Adams, M. W. W.; Johnson, M. K. Resonance Raman Characterization of the Mononuclear Iron Active-Site Vibrations and Putative Electron Transport Pathways in Pyrococcus furiosus Superoxide Reductase. Biochemistry 2002, 41, 9833-9841, DOI: 10.1021/bi025833b

$\underline{\mathbf{5 9}}$ Gardner, J. D.; Pierce, B. S.; Fox, B. G.; Brunold, T. C. Spectroscopic and Computational Characterization of Substrate-Bound Mouse Cysteine Dioxygenase: Nature of the Ferrous and Ferric Cysteine Adducts and Mechanistic Implications. Biochemistry 2010, 49, 6033- 6041, DOI: 10.1021/bi100189h

$\underline{60}$ Fiedler, A. T.; Brunold, T. C. Combined Spectroscopic/Computational Study of Binuclear Fe(I)-Fe(I) Complexes: Implications for the Fully-Reduced Active-Site Cluster of Fe-Only Hydrogenases. Inorg. Chem. 2005, 44, 1794-1809, DOI: 10.1021/ic048739n

$\underline{61}$ Kitagawa, T.; Dey, A.; Lugo-Mas, P.; Benedict, J. B.; Kaminsky, W.; Solomon, E.; Kovacs, J. A. A Functional Model for the Cysteinate-Ligated Non-Heme Iron Enzyme Superoxide Reductase (SOR). J. Am. Chem. Soc. 2006, 128, 14448- 14449, DOI: 10.1021/ja064870d

$\underline{62}$ Tremey, E.; Bonnot, F.; Moreau, Y.; Berthomieu, C.; Desbois, A.; Favaudon, V.; Blondin, G.; Houee-Levin, C.; Niviere, V. Hydrogen bonding to the cysteine ligand of superoxide reductase: acid-base control of the reaction intermediates. JBIC, J. Biol. Inorg. Chem. 2013, 18, 815-830, DOI: 10.1007/s00775-013-1025-1

63 Siiman, O.; Carey, P. R. Resonance Raman spectra of some ferric and cupric thiolate complexes. J. Inorg. Biochem. 1980, 12, 353- 62, DOI: 10.1016/S0162-0134(00)80276-7 
64 Clay, M. D.; Emerson, J. P.; Coulter, E. D.; Kurtz, D. M.; Johnson, M. K. Spectroscopic characterization of the [Fe(His)4(Cys)] site in 2Fe-superoxide reductase from Desulfovibrio vulgaris. JBIC, J. Biol. Inorg. Chem. 2003, 8, 671-682, DOI: 10.1007/s00775-003-0465-4

65 Brennan, B. A.; Cummings, J. G.; Chase, D. B.; Turner, I. M., Jr.; Nelson, M. J. Resonance Raman spectroscopy of nitrile hydratase, a novel iron-sulfur enzyme. Biochemistry 1996, 35, 10068-10077, DOI: 10.1021/bi960163t

66 Hirota, S.; Ogura, T.; Shinzawa-Itoh, K.; Yoshikawa, S.; Kitagawa, T. Observation of Multiple CN-IsotopeSensitive Raman Bands for CN Adducts of Hemoglobin, Myoglobin, and Cytochrome c Oxidase: Evidence for Vibrational Coupling between the Fe-C-N Bending and Porphyrin In-Plane Modes. J. Phys. Chem. 1996, 100, 15274-15279, DOI: 10.1021/jp953190m

67 For both species, analysis of the computed ${ }^{32} \mathrm{~S} /{ }^{34} \mathrm{~S}$ isotope shifts revealed that several modes between 350 and $400 \mathrm{~cm}^{-1}$ contain partial $v(\mathrm{Fe}-\mathrm{S})$ character. The frequencies of these modes were weighted according to the magnitude of their sulfur isotope shifts to obtain the "true" computed v(Fe-S) frequency.

68 Taylor, C. P. S. The EPR of Low Spin Heme Complexes. Biochim. Biophys. Acta, Protein Struct. 1977, 491, 137-149, DOI: 10.1016/0005-2795(77)90049-6

69 Griffith, J. S. Theory of electron resonance in ferrihemoglobin azide. Nature (London, $U$. K.) 1957, 180, 30-1, DOI: 10.1038/180030a0

$\underline{70}$ Fiedler, A. T.; Halfen, H. L.; Halfen, J. A.; Brunold, T. C. Synthesis, Structure Determination, and Spectroscopic/Computational Characterization of a Series of Fe(II)-Thiolate Model Complexes: Implications for Fe-S Bonding in Superoxide Reductases. J. Am. Chem. Soc. 2005, 127, 1675- 1689, DOI: $10.1021 / \mathrm{ja046939s}$

$\underline{71}$ Light, K. M.; Yamanaka, Y.; Odaka, M.; Solomon, E. I. Spectroscopic and computational studies of nitrile hydratase: insights into geometric and electronic structure and the mechanism of amide synthesis. Chem. Sci. 2015, 6, 6280-6294, DOI: 10.1039/C5SC02012C

$\underline{72}$ Stein, N.; Gumataotao, N.; Hajnas, N.; Wu, R.; Lankathilaka, K. P. W.; Bornscheuer, U. T.; Liu, D.; Fiedler, A. T.; Holz, R. C.; Bennett, B. Multiple States of Nitrile Hydratase from Rhodococcus equi TG328-2: Structural and Mechanistic Insights from Electron Paramagnetic Resonance and Density Functional Theory Studies. Biochemistry 2017, 56, 3068- 3077, DOI: 10.1021/acs.biochem.6b00876

73 Badger, R. M. A relation between internuclear distances and bond force constants. J. Chem. Phys. 1934, 2, 128- 31, DOI: 10.1063/1.1749433

74 The mathematical form of Badger's rule is $r_{\mathrm{e}}=\left(C / \mathrm{v}^{2 / 3}\right)+d$, where $r_{\mathrm{e}}$ is the equilibrium bond distance, $\mathrm{v}$ is the vibrational frequency, and $C$ and $d$ are empirically determined constants for a given combination of atoms.

$\underline{75}$ Clay, M. D.; Jenney, F. E., Jr.; Hagedoorn, P. L.; George, G. N.; Adams, M. W. W.; Johnson, M. K. Spectroscopic Studies of Pyrococcus furiosus Superoxide Reductase: Implications for Active-Site Structures and the Catalytic Mechanism. J. Am. Chem. Soc. 2002, 124, 788-805, DOI: 10.1021/ja016889g

76 Scarrow, R. C.; Brennan, B. A.; Cummings, J. G.; Jin, H.; Duong, D. J.; Kindt, J. T.; Nelson, M. J. X-ray spectroscopy of nitrile hydratase at pH 7 and 9 . Biochemistry 1996, 35, 10078-10088, DOI: 10.1021/bi960164l 